NISTIR 7406

\title{
Vehicle Fire Suppression Research Needs
}

Anthony Hamins

National Institute of Standards and Technology Technology Administration, U.S. Department of Commerce 



\title{
Vehicle Fire Suppression Research Needs
}

\author{
Anthony Hamins \\ Fire Research Division \\ Building and Fire Research Laboratory
}

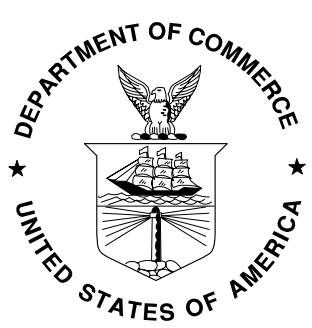

U.S. Department of Commerce

Carlos M. Gutierrez, Secretary

Technology Administration

Robert Cresanti, Under Secretary of Commerce for Technology

National Institute of Standards and Technology

William Jeffrey, Director 


\title{
Vehicle Fire Suppression Research Needs
}

\author{
Submitted to \\ Motor Vehicle Fire Research Institute (MVFRI) \\ 1334 Pendleton Court \\ Charlottesville, Virginia 22901
}

March 1, 2004

Revised: March, 142007

\begin{abstract}
This report identifies research needs in automotive fire protection. The work focuses on the problem of post-collision vehicle fires. Recent fire suppression research is cited with special attention given to results cited in the scientific literature as well as relevant reviewed manufacturer information. The report is broken into several sections that include background information on the post-collision vehicle fire problem, a summary of previous suppression research in vehicles, recent fire suppression research, in general, and specific suggestions for further post-collision vehicle fire suppression research that is needed. The results of a workshop on "Fire Suppression Research Needs" that took place during the 2005 SAE World Congress is described. Several Appendices reproduce pertinent information, regarding suppression technologies for vehicle fire applications, which were obtained on the internet and in this sense act as an archive.
\end{abstract}




\section{Table of Contents}

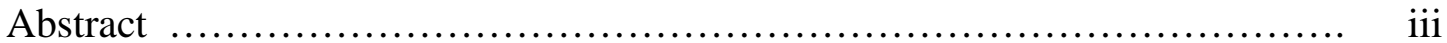

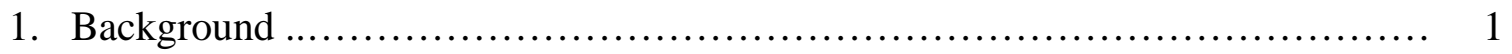

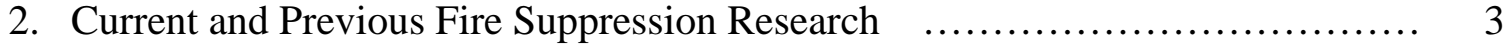

2.1 The Search for Halon Replacements and Alternatives ...................... 3

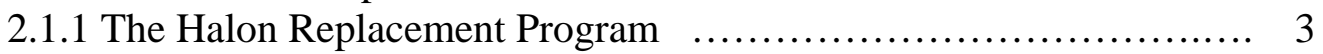

2.1.2 The Next Generation Fire Suppression Program (NGP) ............ 4

2.1.3 Conferences and Workshops on Fire Suppression Research .......... 4

2.1.4 Aircraft and Automobile Fire Protection ........................... 5

2.2 Commercially Available Fire Suppression Technology $\ldots \ldots \ldots \ldots \ldots \ldots \ldots \ldots . \ldots$

2.3 Technology Assessment for Vehicle Fire Protection ........................... 7

2.4 Ford Fire Suppression Research for Post-Rear-Impact fires in the Crown Victoria

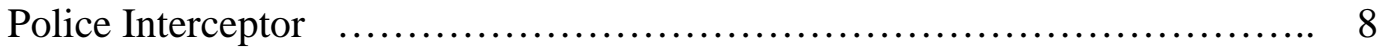

2.5 Other Recent Fire Suppression Experiments............................. 10

2.6 Powder Panels ............................................................ 11

2.6.1 Operation ...................................................... 11

2.6.2 Previous Vehicle Fire Testing Using Powder Panels $\ldots . \ldots \ldots \ldots \ldots \ldots \ldots . . . . .12$

3. Ideas for Vehicle Fire Protection Research Directions .......................... 13

3.1 The Character of Post-Collision Fires ................................ 13

3.2 Workshop on Vehicle Fire Suppression................................ 16

3.3 Development of Standardized Fire Suppression Test Protocols .............. 17

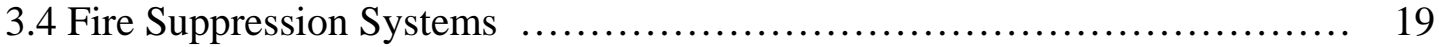

3.4.1 Powder Panels ................................................... 20

3.4.2 Foams ........................................................... 20

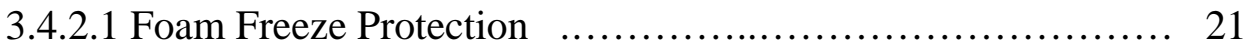

3.4.3 Solid Propellant Generators and Their Hybrids ....................... 22

3.4.4 Other Suppressants ............................................ 22

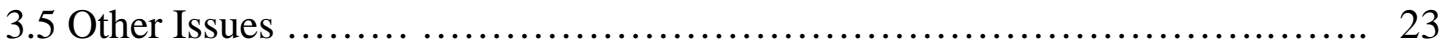

3.5.1 Economic Survey ........................................... 23

3.5.2 Firewall on Demand............................................ 23

3.5.3 Crashworthiness ................................................ 23

3.5.4 Computer Fire Models............................................. 23

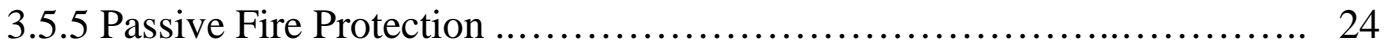

4. Summary and Recommendations........................................ 24

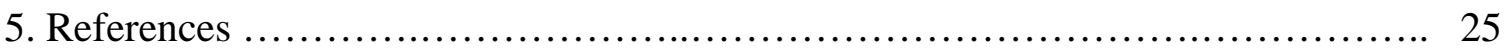

Appendix A. Naples Daily News article on the suppression system on Ford's Crown

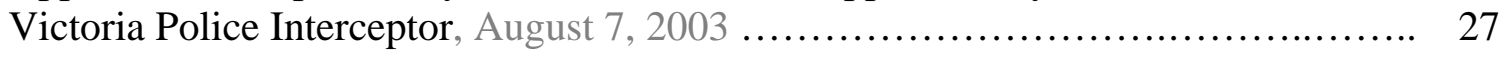

Appendix B. Ford Motor Co. Information on Fire Suppression,....................... 29 
Appendix C. Ford Motor Co. News Release of July 28, 2006

32

Appendix D. Information on Ford's Automatic Fire Suppression System

Appendix E. Summary of Workshop on Research Needs for Suppression of Vehicle Fires 


\section{Vehicle Fire Suppression Research Needs*}

This report identifies research needs in automotive fire protection with an emphasis on fire suppression. The report focuses on the problem of post-collision vehicle fires and is broken into several sections including background information on the post-collision vehicle fire problem, a summary of previous suppression research in vehicles and recent fire suppression research in general. Recent fire suppression research is cited with special attention given to results in the open scientific literature as well as relevant manufacturer supplied information. Specific suggestions for further post-collision vehicle fire suppression research are made. The last section lists cited references. A number of appendices are also included. The first four reproduce information found on the internet, are also included. The last one summarizes the results of a workshop on automobile fire suppression.

\section{Background}

Fires in vehicles that are not involved in a collision can be costly in terms of repairs, but are not typically a concern in terms of life safety. In a post-collision vehicle fire, however, egress from a vehicle may be impossible and therefore the fire can be the most significant event leading to a fatality. In cases involving a post-collision vehicle fire, the presence of an effective fire suppression system would be highly beneficial in reducing fatalities.

The post-collision vehicle fire problem is unique. Consideration of the details of the fire scenario is important in the search for possible solutions. A post-crash vehicle fire, unlike many other fire scenarios, is characterized by several problems that combine to create a complex and challenging situation for active fire protection. Each of these challenges restricts the range of possible fire suppression options. They include the following:

- The post-collision vehicle fire problem is not well documented. In particular, early fire time lines have not been adequately researched, so that there is little information regarding the initial fuel (motor oil, gasoline, transmission fluid, power steering fluid, etc.), its relative location, spatial distribution, and volume. The best available study is

\footnotetext{
* This report was financed by the Motor Vehicle Fire Research Institute (MVFRI) to assist in the identification of research needs in automotive fire protection. The National Institute of Standards and Technology (NIST) is applying its expertise in fire science to this program because of the potentially high impact of this program on vehicle fire safety in the United States. In analyzing data available in the literature, certain vehicles, equipment, instruments, or materials are identified in this report in order to specify the experimental procedure adequately. In no case does such identification imply recommendation or endorsement by the National Institute of Standards and Technology, nor does it imply that the fire safety of a particular vehicle is superior or inferior to any other. In addition, certain trade names and company products are mentioned in the text to specify adequately the experimental procedure and equipment used or to identify types of currently available commercial products. In no case does such identification imply recommendation or endorsement by the National Institute of Standards and Technology, nor does it imply that the products are necessarily the best available for the purpose.
} 
that of Scheibe et al., [2001], which contains 35 case studies. It may be the best documentation in the literature of ignition source and first fuel.

- The geometry of every vehicle make and model differs, which can influence ignition, fire spread and growth.

- Post-crash vehicle fires differ from fires in intact vehicles, as the geometric configuration may be modified by the collision in ways that cannot be precisely defined beforehand.

- Suppression system placement is restricted by limitations associated with vehicle function and crash survivability.

- Practical considerations limit the mass and volume of an on-board suppression system.

- Ambient factors such as temperature, wind, and incline of the road may impact suppression system performance.

- Vehicle fires occur in a compartment that is partially open to the environment, which can lead to suppressant loss.

- The particular crash scenario will govern the rate and relative location of fuel leakage, and these details will influence the severity of the fire and the probability of successful fire suppression.

- A high-speed vehicle crash can lead to vehicle movement tens of meters from the location of the collision, over a period of several seconds. Once the vehicle is stationary, a trail of fuel may extend beyond the vehicle footprint, due to fuel leakage during vehicle movement and/or due to the incline of the road surface.

- Depending on the collision scenario, it is also possible that a pool fire could be situated around the footprint of a vehicle tire. A tire would create a large flow obstacle for a stream of suppressant, making suppression more challenging.

- The time of initiation of a fire after a collision can vary. A fire can begin immediately after a collision or several minutes later as was observed in a front-end barrier crash that was conducted as part of the DOT/GM Agreement [Jensen et al., 1999]. In that event, an energized, collision-damaged, thermoplastic battery case was observed to be the initial fuel source.

There are several modes of post collision vehicle fires, including frontal collision underhood fires, rear collision fuel-fed fires, and rollover fires. Front collision underbody fuel-fed fires also occur. Rollovers fires are more frequent then fires in rear collisions and about half as frequent as fires in frontal collisions. About half of the rollovers have other collisions prior to the rollover which adds to the complexity of the scenario. Most rollover fires occur with the vehicle on its side or roof. Consequently, vehicle orientation needs to be considered in a fire suppression system.

For simplicity, this report focuses on frontal collision underhood fires and rear collision fuel-fed fires, Some differences between these configurations are evident:

- there is less distance traveled after frontal collisions.

- fuel trails may be less important in frontal collisions.

- underhood fluids may play an important role in fires after a frontal collision.

- many more and different ignition sources play a possible role in underhood fires. 
Understanding the differences between these two types of post-collision fires is important in trying to develop practical and effective mitigation strategies. Rear end fuel-fed fires can be characterized as unconfined, that is the fire is not contained in a closed compartment. Underhood fires, on the other hand, occur in a compartment that is only partially open to the environment. Suppression in the open is more challenging as suppressant unless deliberately directed, will not flow towards the fire source.

\section{Current and Previous Fire Suppression Research}

To appreciate the range of possible solutions that may address the automobile fire suppression problem, it is instructive to understand applicable technology developments and recent fire suppression research efforts in related applications as well as research specifically focused on vehicle fire protection.

\subsection{The Search for Halon Replacements and Alternatives}

Fire suppression research has been conducted over the last one-hundred years, but not with the level of support as provided by the recent search to find a suitable replacement for the fire suppression agent, halon $1301\left(\mathrm{CF}_{3} \mathrm{Br}\right)$. Over the last ten plus years, a global effort has been in place to find a halon replacement, whose manufacture was halted due to its deleterious effects on stratospheric ozone. In the U.S., much of the work was sponsored by the Department of Defense (DoD), which has conducted fire suppression research primarily to protect the integrity of various types of weapon systems and focused mainly on aircraft fire suppression. The research on halon alternatives has revitalized fire suppression research, illuminating many new concepts for fire suppression applications.

The Halon Replacement Program for Aviation and the Next Generation Program (NGP) focused mainly on aircraft fire suppression. Research on halon alternatives has revitalized fire suppression research, illuminating many new concepts for fire suppression applications.

The research conducted through the NGP and Halon Replacement programs and that presented at the Halon Options Technical Working Conference (HOTWC) provide valuable information relevant to the vehicle fire problem. The lessons learned through the DoD work provide a basis for developing strategies to address vehicle fire protection. Indeed, much has been learned through both the successes and the failures of the DoD sponsored projects As many of the same challenges and issues are common to the aircraft and vehicle fire suppression problems.

\subsubsection{The Halon Replacement Program}

The DoD, in conjunction with the U.S. Federal Aviation Administration (FAA), and the aviation industry, sponsored the Halon Replacement Program for Aviation which provided support for a large number of fire suppression related projects. The work involved the selection of one chemical from a large list of possible replacement agents for halon 1301. 
The Halon Replacement Program attempted to evaluate many fire suppression chemicals for selection as a halon replacement, until a better long-term solution could be found. The Program also supported research to determine the most significant factors, which would impact the quantity of an agent required to suppress a fire. A major outcome of the program was the development of knowledge to specify engineering criteria for suppression system design. This allowed system designers to estimate the amount of agent needed to provide equivalent aircraft protection as was afforded by halon 1301 .

\subsubsection{The Next Generation Program}

As a follow-up program, the Next Generation Fire Suppression Technology Program (NGP) was sponsored by the Strategic Environmental Research and Development Program (SERDP), and under the auspices of the U.S. Department of Defense (DoD), Department of Energy (DoE), and Environmental Protection Agency (EPA). The goal of the NGP was to develop and demonstrate, by 2005, technology for economically feasible, environmentally acceptable and user-safe processes, techniques, and fluids that meet the operational requirements currently satisfied by halon 1301 systems. Originally, the Program addressed aircraft, ships, land combat vehicles and critical mission support facilities. Whereas fire suppression in these DoD applications differs in many respects from the automobile fire suppression problem, there are also similarities.

The topics covered by NGP have included new flame suppression chemistry, the development of suppressant screening tests focused on aircraft applications, new and improved aerosol suppressants, improved suppressant delivery, viability of new suppressant technologies, and improved fuel tank inertion. Recent studies in flame suppression chemistry have investigated low boiling point compounds, the effectiveness of fluoroalkyl phosphorus compounds, and agent stability during long-term storage. Research on improved suppressants has investigated solid propellant fire extinguishers, the dispersion of suppressants at low temperature, suppressant dynamics, enhanced powder panels, mechanisms of unwanted accelerated burning, enhanced extinguishment using intumescent coatings, suppressant concentration measurements, analysis of the world of useful chemicals, identification of possible alternative suppressants, a suite of screening tests and guidance for their use, methods for determining and comparing the total life-cycle costs of new fire suppression technologies, and identification of diagnostics needed to characterize the outcome of fire tests. A number of these investigations have bearing on the vehicle fire suppression problem and are discussed below.

\subsubsection{Conferences and Workshops on Fire Suppression Research}

Industry, academic institutions, and international organizations have conducted fire suppression research, beyond the Halon Replacement Program and the NGP Program. Much of the most important recent fire suppression research is documented in the proceedings of the Halon Options Technical Working Conference [HOTWC, 19912006], an annual conference that was dedicated to applied fire suppression research. Since 1991, conference papers have addressed a variety of relevant topics, including 
advanced chemicals and agents, total flood applications, passive fire suppression, suppressant mixtures, water mists and sprays, and non-halon alternatives. Other national and international conferences and workshops on combustion and fire research have included papers on fire suppression, although there have been few studies that directly address vehicle fire suppression research ${ }^{1}$. Some of these conferences have had entire sessions devoted to fire suppression research, but the emphasis has usually been on structural or residential applications, typically involving water sprinklers or water mist. In addition, there are many international journals that address fire and combustion research, and include contributions on fire suppression research ${ }^{2}$. A review, however, shows that the journals do not contain research papers that address fire suppression in vehicles. The exceptions to this is a recent SAE Conference, in which a number of papers on vehicle fire suppression research were highlighted ${ }^{3}$.

\subsubsection{Aircraft and Automobile Fire Protection}

There are many issues that are common to vehicle fires and fire scenarios that are of concern to the DoD and FAA. The Halon Replacement and the Next Generation Programs addressed some of these issues. A major focus of these Programs was aircraft fire protection. Fire suppression systems on-board aircraft are designed to protect the engine nacelle, the dry bay, cargo areas, and in a number of cases, the aircraft auxiliary power unit and the on-board lavatory.

The engine nacelle is a ventilated compartment encasing the aircraft engine. The space contains electronic and plumbing lines that carry fuel and hydraulic fluids. Suppressant mass requirements are driven to a large extent by the presence of hot surfaces that have been shown to cause re-ignition of a fuel leak. In a sense, an aircraft nacelle is similar to the underhood vehicle engine compartment, except that a vehicle engine compartment is partially open to the environment, which makes active fire suppression very challenging. It should also be noted that ventilation flows in the two volumes are very different. Both flows are very complex and have significant impact on fire suppression strategies.

Dry bay fire protection is a concern for military aircraft encountering incoming ballistic rounds that can lead to a complex set of fast-occurring events involving the presence of fuel splashing and hot shrapnel, leading to a deflagration, shock wave formation, and possible over-pressurization of the dry bay compartment.

\footnotetext{
${ }^{1}$ International Aircraft Fire and Cabin Safety Research Conference, Atlantic City, NJ; Proceedings of the Interflam Conference, Edinburgh, Scotland; Proceedings of the International Symposia on Fire safety Science, International Association of Fire Safety Science (IAFSS), (1985 to present); Proceedings of the Combustion Institute (1928-present); Proceedings of the International Conference on Fire Research and Engineering, Society of Fire Protection Engineers, 1995-current; Proceedings of the First International Conference on Fire Suppression Research, Stockholm, Sweden, 1992; Proceedings of the International Microgravity Combustion Workshop, Cleveland, Ohio.

${ }^{2}$ Combustion and Flame, Combustion Theory Modeling, Fire Safety Journal, Combustion Science Technology, Journal of Applied Fire Science, Journal of Fire Protection Engineering, NFPA Journal, Progress in Energy and Combustion Science, and the Society of Fire Protection Engineers (SFPE) Journal. ${ }^{3}$ Session C on Fire Suppression, B-27 Forum, Society of Automotive Engineers World Congress, Detroit, MI, April 13, 2005 (see Dierker et al., 2005; Santrock and Hodges, 2005;.
} 
Some similarities of vehicle fires and the fire scenarios of concern to the DoD and FAA include the following:

- Egress is not possible in many fire scenarios

- Fires typically involve hydrocarbon based fuels

- Catastrophic fire events may initiate rapidly and threaten life safety within a couple of minutes

- Fires occur in compartments that are partially open to the environment or are cluttered by machinery and parts

- Fire scenarios vary depending on many factors

- The presence of hot surfaces play a role including the potential for re-ignition

- Agent toxicity, environmental impact, stability during long-term storage, compatibility with storage container materials, corrosion, cold weather storage, system maintenance requirements, are a concern.

- Suppression system effectiveness and reliability

Some major differences between vehicle fires and the fire scenarios of concern to the DoD and FAA include the following:

- The basic automotive fuel (i.e., gasoline) is more volatile than common DoD fuels (i.e., jet fuel or diesel).

- Diesel or jet fuel tanks can have an explosive vapor mixture in the tank; gasoline tanks do not as they are too rich (greater than the upper flammability limit, at least at ambient $\left(20^{\circ} \mathrm{C}\right)$.

- New model vehicles are loaded with thermoplastics, whereas many DoD applications do not have thermoplastics in the initial fire zone.

- The quantity of fuel in most DOD applications is typically much larger.

- The automotive fire scenarios do not involve protection of compartments such as an aircraft dry bay or ventilated compartments such as a typical aircraft engine nacelle. In this sense, the geometric configuration of the automotive fire problem is not similar to most aircraft scenarios.

For the dry bay scenario, very fast suppressant release is required for protection. The main similarities between the dry bay fire scenario and a rear-end collision and subsequent fuel-fed fire are the rate at which the event transpires and the occurrence of fuel atomization or fuel splashing in the presence of ignition sources at multiple spatial locations. The main difference between the scenarios is that the dry bay is a closed compartment, whereas an underbody fuel fed fire is only partially enclosed. This difference has significant implications in terms of fire suppression strategies and suppressant mass requirements.

Fire suppression systems for aircraft are highly specialized. Once a suppression system is designed for a particular engine nacelle type, experimental verification is required to demonstrate suppressant distribution in an attempt to certify the fire protection system performance. The design of effective vehicle fire suppression systems will require a high level of sophistication in engineering design and experimental demonstration. This is exemplified by the complexity of the recent work by Ford Motor Co. to provide an underbody fire suppression system as an option on its Crown Victoria police vehicle for 
the 2005 model year [Dierker, 2005; Ford, 2006]. The Ford suppression system is discussed in some detail in Section 2.4 below.

The research conducted through the NGP and Halon Replacement programs and that presented at the HOTWC provide valuable information relevant to the vehicle fire problem. The lessons learned through the DoD work provide a basis for developing strategies to address vehicle fire protection. Indeed, much has been learned through both the successes and the failures of the DoD sponsored projects As many of the same challenges and issues are common to the aircraft and vehicle fire suppression problems.

\subsection{Commercially Available Fire Suppression Technologies for Vehicles}

It may be possible to borrow or modify current suppression technology to effectively address the vehicle fire problem. Commercial suppression systems are available for fire protection in trains, boats, mining equipment, military equipment, and aircraft. The U. S. Army, for example, uses automatic fire suppression systems in the engine compartments of armored vehicles [Bolt et al., 1997]. Some types of vehicles have been fitted with commercially available active suppression systems. These include buses, trucks, heavy equipment, and specialized vehicles such as racecars [e.g., Hodges, 1995]. In racing applications, both the passenger and the engine compartments may be protected using manual and/or automatic suppressant delivery systems.

There has been some reported work on suppression systems for civilian automobile applications. Lim et al [1997] report that a German automobile manufacturer has developed an automatic fire suppression system for the engine compartment of its passenger cars. Lim et al. [1997] also report that an automatic fire suppression system has been developed for the engine compartment of passenger automobiles in the U.K. using halon alternatives. There has been no confirmation of this information and there is no evidence on the internet to suggest that vehicles are being manufactured with on-board suppression systems in Europe or anywhere else. In 2004, Ford Motor Co. announced that it will produce a hybrid foam/solid propellant gas generator fire suppression system as an option on its 2005 Crown Victoria Police Interceptor line of vehicles [Ford, 2004a]. Fire Panel has been selling a powder panel as an aftermarket addition for protection of fuel tanks of automobiles in the event of a rear-end collision [Fire Panel, 2006]. Comprehensive independent testing of the effectiveness of these on-board suppression systems has not been reported.

\subsection{Technology Assessment for Vehicle Fire Protection}

Bennett [1998] with participation by Santrock and Kononen of General Motors and Hamins of NIST conducted a comprehensive survey and assessment of available technologies that could be applied to the vehicle fire protection problem. The study included a literature search and a survey, which was sent to several hundred manufacturers of fire mitigation technologies. A rating process, based on expert judgment, was created to evaluate the relative merits of the different technologies for possible motor vehicle applications. A portion of the survey addressed fire suppression technologies and strategies. 
The survey was sent to approximately 300 companies who offered technologies that might improve the fire safety of passenger vehicles. The technologies could be used either off the shelf or with modifications. Foreign companies with special products were also considered. The set of requested information was reduced to the minimum necessary to assess the potential impact of a technology's use in automobile applications. It was understood that many of the manufacturers may not have portions of the detailed data that were requested, and in fact, significant portions of many survey forms were not completed. Evaluation of the data was then performed based on engineering judgment. A listing of the detailed survey results is given in Bennett [1998]. A total of 38 companies returned surveys. Forty products were considered active systems (including 11 detector products), 12 were passive systems, and 11 were fire resistant materials.

The relative merits of active fire suppression systems, passive fire protection systems and fire resistant materials were considered for possible motor vehicle fire safety applications. Active fire suppression systems that were evaluated included clean agents, dry chemicals, water mist, aqueous film forming foam (AFFF), gas generators using pure gas and hybrids that dispense clean agents and dry chemicals, pyrotechnic aerosol systems, tubular fire extinguishing systems and explosion suppression systems. The report described the various technologies and assessed the potential of the product to improve post-collision automotive fire safety. The rating protocol was based on engineering judgment and without the benefit of crash test data or field testing. The rating system considered the various technology types in terms of required weight, reliability, crashworthiness, re-ignition protection, toxicity, cost, safety, and availability. The rating system made no distinction among highly variable vehicle designs, but did separately consider engine compartment fires and underbody fuel-fed fires. The results were broken into three categories: those with the highest potential as vehicle fire suppression systems and those with lower or moderate potential as vehicle fire suppression systems.

The highest evaluation ratings went to aerosol extinguishers, conventional powder extinguishers systems, conventional water mist systems, conventional water based foam systems, and gas generator/hybrid systems for the engine compartment fires. For the rear-end collision and underbody fuel-fed fires, ratings of most of the suppression systems were also grouped into three categories and the ratings were similar to the results for the engine compartment.

It should also be noted that passive fire protection systems such as self-sealing fluid lines, enhanced crashworthiness of the fuel tank, and fluid shut-off devices were rated highly.

\subsection{Ford Fire Suppression Research for post-rear-impact fires in the Crown Victoria Police Vehicle}

As part of its Police Officer Safety Action Plan, Ford Motor Co. announced in 2003 that it was actively evaluating fire suppression technologies to defend against ruptured fuel tanks and subsequent underbody fuel fed fires [Ford, 2003a]. The work was in apparent response to concern regarding fires due to fatalities associated with a number of highspeed rear-end impacts in parked Crown Victoria police vehicles. Between 1983 and 
2003, there were fourteen documented cases of officers who died in vehicles when the fuel tank caught fire after a rear end collision [Porretto, 2003; see Appendix A].

To address this issue, Ford recently announced that its engineers tested eight fire suppression systems. Part of the testing involved fires in moving vehicles. The test protocol was designed to simulate the movement experienced by a stationary vehicle

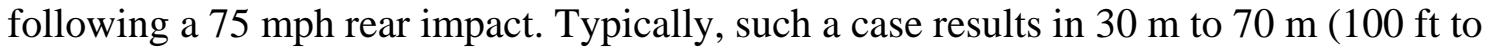
$200 \mathrm{ft}$ ) of movement of the struck vehicle. Ford reported that their test protocol guaranteed both a fuel leak and ignition of the fuel. A rough description of the Ford testing protocol was recently released on their website [Ford, 2006], and is reproduced in its entirety in Appendix D of this report.

Among its findings, Ford listed the following as significant conclusions reached during the testing [Ford, 2003c]:

- Fuel leaks that begin near the point-of-impact may leave a 75-to-200-foot fuel trail to the point-of-rest of the vehicle.

- Ignition of this fuel trail can occur when the deformed vehicles scrape the road surface and create sparks while passing through or along the fuel trail.

- An ignited fuel trail can initiate a fire at the vehicle's final point-of-rest if there is continuing leakage of a sufficient amount of fuel at the point-of-rest.

- The fire is not intense at the passenger compartment until the vehicle is stationary, and unless there is a continuing leak at the point-of-rest.

- Challenges associated with packaging the fire suppression substance and system, while still allowing the vehicle to function effectively as a police vehicle, necessarily limit the quantity of the available fire suppression substance.

- The optimal time for deploying the limited amount of the fire suppression substance is near the point-of-rest, which can be seconds after and more than 200 feet beyond the point-of-impact.

- Wind, ground surface and road grade are factors in fire propagation.

- No vehicle fire suppression system can extinguish a fire fed by large quantities of gasoline.

- Liquid fire suppressants combined with surfactants performed better than foams or powders due, in part, to the ability of that substance to spread - like gasoline beyond the direct reach of the deployment nozzles and to cover the gasoline. This combined substance more effectively reduced the risk of a re-ignition at the point-ofrest of the vehicle when the fire is not completely extinguished at, for example, the fuel trail or on the protected/outboard side of the rear wheels.

Ford began offering fire-suppression technology as an option on its 2005 model Crown Victoria Police Interceptor vehicle. This is a watershed event in terms of fire safety for vehicles in the United States. After a broad preliminary research effort, Ford selected Aerojet, an aerospace and defense company based in Sacramento, California, to jointly pursue further development of the fire suppression technology for the police vehicle application. Aerojet's technology uses a pyrotechnic gas generator to deploy a combination liquid fire suppressant and surfactant. The pyrotechnic system is similar to 
an air-bag deployment system, but in this application it is used to release fire suppression chemicals [Dierker, 2005; Ford, 2006]. Ford reported that a surfactant was used, because it reduces the surface tension of the liquid fire suppressant, thereby enabling the liquid to spread more quickly and completely. Ford uses advanced electronics modules to measure post-impact vehicle movement and to determine the optimal time for deployment of the fire suppression system. Ford has not offered suppression system retrofit for older models, maintaining that the sophisticated electronics required for crash-activated and delayed deployment prohibit offering an after-market product. In May 2003, Ford and Aerojet reported that they planned to conduct about 30 fire suppression tests to learn more about the effect of varying fuel quantity, fuel spill rates, re-ignition, discharge timing and shadow (fire behind the rear-wheel) effects.

The Ford fire suppression test program is unique and any information released to the public bears careful consideration. The lessons learned from Ford's research program are extremely important as they represent an extensive set of reported research results. Any vehicle fire suppression system must function under real-world conditions. A comprehensive on-board suppression system must be crashworthy, and must address fuel trails, and vehicle travel after collision impact. The Ford system used a strategy to address these concerns. Some amount of information on the test protocol is available, but unfortunately it is not in the form of written reports. Some information is available through what can only be termed as adversarial communication involving Ford Motor Co. and Fire Panel Inc., a company whose product was tested during the Ford Fire Suppression Test Program. From documentation on the Fire Panel and Ford websites [Fire Panel, 2006; Ford, 2006], some amount of information regarding the details of the test protocol can be ascertained. In particular, a report to Fire Panel by Hughes Associates [2003] quotes a deposition taken from Joseph B. Dierker, a Ford Employee and technical leader of the Ford fire suppression project team, regarding the test protocol. Description of the suppression test protocol is quite detailed and offers an understanding of the experimental procedure used by Ford. For the design of future fire suppression testing, it would be useful to have complete documentation of the Ford Fire Suppression Test Program. Detailed reports of the experimental findings would foster the development of post-collision fire suppression systems that would benefit the public.

\subsection{Other Recent Fire Suppression Experiments}

NIST recently performed a series of experiments on the effectiveness of fire suppressants in simulated post-collision engine compartment and underbody fires. General Motors financed the research pursuant to an agreement between GM and the Department of Transportation. NIST tested both traditional and emerging active fire suppressants. These included dry powders, inert suppressants, compressed liquefied halogenated compounds, and a number of prototype suppression concepts such as tubular suppression systems, solid propellant generators, and aerosol generators. A number of experimental approaches were investigated to appraise the feasibility of fire suppression using the representative suppressants.

Hamins [2000] investigated the effectiveness of fire suppressants as an intervention strategy in simulated post-collision vehicle fires. General Motors Corp. financed the 
study pursuant to an agreement between General Motors and the United States Department of Transportation. A number of experimental protocols were developed to appraise the feasibility of extinguishing fires using common and emerging types of suppressants. Several experimental configurations were investigated including both fullscale and reduced-scale engine compartment and underbody fires. Several fire suppressants were selected for testing. These included dry powders, clean suppressants, and a number of prototype devices. The report describes the experimental results with an emphasis on the relative performance of the suppressants and the influence of various parameters associated with the vehicle itself (e.g., geometry) or the suppressant (e.g., delivery rate). Experiments were performed using both laboratory test devices and a static uncrashed mid-size passenger vehicle. Long fuel trails extending beyond the confines of the vehicle and environmental factors such as wind were considered. The results showed that it is highly improbable that an on-board fire suppression system will be able to extinguish all engine compartment and underbody fires. Many suppressant types were found to be impractical for post-collision engine compartment applications. Of the systems tested, solid propellant gas generators (SPGG) were the most effective.

Subsequent suppression testing using SPGG was performed by Santrock and Hodges [2002] in a crash test and in three static tests in previously crashed vehicles. SPGG suppression was unsuccessful in the moving crash test with a fire burning power steering fluid ignited on a hot manifold. In the static vehicles tests, the SPGG extinguished the fires, but with fluid continuing to leak onto an energized hot surface, re-ignition was observed.

Full-scale underbody experiments by Hamins [2000] showed that suppression of a (333 mL volume) gasoline pool fire was achieved with less than $300 \mathrm{~g}$ of ABC and BC powder suppressants when the fuel was located under the vehicle footprint for low wind conditions. If a fuel puddle in an underbody fire extended beyond the vehicle footprint and if moderate to high winds were present, then the powder suppression system failed to reliably extinguish the fire.

Santrock and Hodges [2005] report on a prototype fire suppression system installed in full-scale vehicle crash tests and static vehicle fire tests. The system consisted of two Solid Propellant Gas Generators and two optical detectors installed on the hood bottom of the test vehicle. A vehicle crash test and a series of static vehicle fire tests were performed to determine the effectiveness of this prototype fire suppression systems in extinguishing fires in the engine compartment of a crashed vehicle. The results indicate that dynamic factors in a crash such as vehicle crush, vehicle movement, wind, and reignition of fuel after release and dispersal of agent (reflash) can substantially reduce the effectiveness of an automatic fire suppression system in extinguishing a post-crash fire.

\subsection{Powder Panels}

\subsubsection{Operation}

Powder panels are a particularly intriguing passive fire protection system. The NGP (see Section 2.2.1) recently supported an investigation on the effectiveness of powder panels for fire suppression. Powder panels were first developed and used by the British Royal Aircraft Establishment [Cyphers et al., 2003]. The panels are relatively simple devices composed of molded thermoplastic that contains a fire suppressant powder. A variety of 
fire suppressants have been tested as the active agent in powder panels including Monnex, KDKI, $\mathrm{Al}_{2} \mathrm{O}_{3}, \mathrm{Al}_{2} \mathrm{O}_{3}$ with $\mathrm{KI}, \mathrm{Al}_{2} \mathrm{O}_{3}$ with $\mathrm{SiO}_{2}$, Purple $\mathrm{K}$, potassium bicarbonate, and 10\% acetate in water [Cyphers, 2003].

Powder panels have been applied to the lining of aircraft dry bays to provide passive, lightweight, fire protection against ballistic impact. Dry bay areas are zones in military aircraft that store fuel. The panels are strategically positioned such that they are stationed directly in front of vulnerable fuel storage containers. When a projectile penetrates the panel, the agent from the panel is released to inert the space vulnerable to a fuel spill and fire. Cyphers et al. [2003] conducted a survey on the use of powder panels. Cyphers reported that the use of powder panels in dry bay protection of rotary wing aircraft has been established, for example, in the Navy UH-1Y Huey and AH-1W Super Cobra aircraft. In addition, the V-22 Osprey Tiltrotor aircraft uses powder panels extensively. Powder panels have been examined widely for military combat land vehicles, such as tanks and armored personnel carriers.

Cyphers [2003] conducted a series of reduced-scale experiments to investigate a number of enhanced performance concepts for application of powder panels. Cyphers [2003] has attempted to create a "reactive" powder panel that adds energy to enhance delivery effectiveness of the powder. Preliminary tests of the enhanced powder panel design have been encouraging. As part of the NGP program, research continues to examine means for effecting greater powder release, better dispersion of powder, longer powder suspension in the air to prevent the possible ignition of a fire for longer periods of time, and panel durability. Ongoing optimization test variables include panel materials, and thicknesses, powder loading (density of powder inserted into a given panel size), rib design, and the assembly process. Preliminary tests have shown that the innovations in powder panel design yields improved performance over traditional powder panel designs [Cyphers et al., 2003]. Fire Panel has made this technology commercially available for fuel tank vehicle fire protection [Fire Panel, 2006].

\subsubsection{Previous Vehicle Fire Testing using a Powder Panel}

Bennett [2005] describes the Fire Panel technology as designed to prevent post-collision vehicle fires. The Fire Panel consists of ABC dry powder (mono-ammonium phosphate) encased in a custom molded thermoplastic assembly [Bennett, 2005; Hughes Associates, 2003]. Fire Panel was recently tested by Ford during its Crown Victoria Fire Suppression Testing program. Some details of the test procedure are available (as mentioned in Section 2.4 above) in the form of a letter from Hughes Associates, a consulting firm hired by Fire Panel Inc. The letter quotes from a deposition taken from Joseph Dierker, an employee with Ford Motor Co., who led the recent Ford fire suppression testing [Hughes Associates, 2003].

The Fire Panel assembly was attached to the outer surface of the fuel tank. Upon collision, the fire panel is designed to shatter and release its powder into the air, thereby preventing flame propagation through a gasoline vapor/ air mixture, which may be present after a rear-end vehicle impact. The design attempts to inert the zone about the panel as it crushes and releases its powder, thereby preventing ignition and flame 
propagation in the region where sufficient powder concentrations are present. After evaluating and performing one test on this technology, Ford [2003c] concluded that the Fire Panel is not effective. Ford's web site stated that:

- Fire Panel releases its fire suppressant powder at the point-of-impact. Little or no powder is released at the critical time and place of the point-of-rest of the vehicle.

- The technology offers little or no protection against fires occurring at the vehicle's point-of-rest; if the fuel trail is ignited or any other ignition source is present after the time and place of impact, the Fire Panel technology provides little or no benefit.

- The powder distribution can be adversely affected by wind and other weather conditions.

- Moisture and road debris trapped between the $6 \mathrm{~mm}(1 / 4 ")$ gap between the Fire Panel and the fuel tank could cause degradation of the steel fuel tank. Either of these concerns could lead to significant out-of-warranty maintenance problems, and potentially degrade fuel system safety.

The Fire Panel website attempts to refute each of the Ford conclusions [Fire Panel, 2006]. It will be interesting to follow the effectiveness of these fire protection systems as information on their performances in actual fire incidents become available.

\section{Ideas for Vehicle Fire Protection Research Directions}

This Section presents ideas on automotive fire suppression research needs. While an infinite number of research approaches are possible, to limit the many possible research directions to those that may be most fruitful, a number of prioritized ideas are proposed.

Some underlying assumptions and simplifying premises are first presented.

- For life safety, a fire protection system must function post-collision and must provide on the order of $10 \mathrm{~min}$ to $30 \mathrm{~min}$ of protection for vehicle passengers to be effectual. The suppression system must provide protection almost immediately as fire may enter the passenger cab within minutes depending on the fire scenario.

- Fire protection systems are not essential to save lives and serious injuries in noncollision situations. However, a non-crash underhood fire protection system may be justified based on the reduction of property damage, and may also lead to a reduction of injuries during crashes that result in fires. The exact time needed is related to time needed for emergency response by authorities. The time required for rescue represents a threshold for effectiveness of a fire protection system. Systems that are less successful are less deserving of development.

- The simpler the fire protection system, the better. This is particularly important when considering system reliability. Systems that rely on the use of multiple pieces of hardware pose a higher risk in terms of malfunction. For example, suppression systems that require distinct detection and activation hardware are more complicated than those that are bundled into one system. In the same manner, systems that 
passively activate by design are not dependent on the signal from a detector, which have been observed to fail in recent crash tests [Santrock and Hodges, 2002].

- Previous research and experience in automotive fire safety should be closely examined. Lessons learned should be exploited and the open literature should be closely scrutinized.

- Any vehicle fire suppression system must be crashworthy. Field testing of any proposed system must be conducted under realistic conditions.

- A suppressant should be delivered soon after ignition occurs, or possibly even before ignition. Once a fire spreads and grows, it is more difficult to extinguish, simply because the suppressant must act to inert larger volumes as well as surfaces that may be heated to higher temperatures.

The following is a list of suppression research ideas and may be considered a starting point for the continued development of a vehicle fire suppression research program.

\subsection{The Character of Post-Collision Fires}

An engine compartment contains combustible substances including gasoline, hydraulic fluids, windshield washer fluid, anti-freeze, engine and brake oils, rubber, thermoplastics, and possibly magnesium. Several ignition sources may be present in a post-collision vehicle including friction sparks generated during the collision, hot surfaces (e.g., exhaust manifold or catalytic converter) to which flammable fluids (e.g., gasoline, windshield washer fluid) or combustible fluids (e.g., motor oil, transmission fluid) might be exposed, or shorted wires that could generate electrical sparks [Jung et al., 1997]. It should be noted that flammable liquids have flashpoint temperatures between $32{ }^{\circ} \mathrm{C}$ and $60{ }^{\circ} \mathrm{C}$, while combustible liquids have flashpoint temperatures above $60{ }^{\circ} \mathrm{C}$. Understanding the early moments of a post-collision vehicle fire, that is, the initial interaction of ignition sources and combustible materials, would be helpful in developing appropriate fire suppression strategies and test protocols. A clear understanding of the identity of initial fuel sources, ignition sources, and early fire time-lines would provide a realistic basis for formulating appropriate fire intervention strategies. Some work in this regard has been reported [Ragland and Hsia, 1998].

High quality data is needed to allow researchers to focus on solutions to the vehicle fire problem. Without statistically meaningful information, the development of fire suppression strategies may be misdirected. Informed with verified information on fire ignition sources and mechanisms, researchers would be able to focus on actual rather than hypothetical fire scenarios. Detailed information may be useful in developing fire suppression and fire protection strategies for vehicles. It may be possible, for example, to provide local protection for particularly vulnerable components. This may involve strategies to prevent ignition or achieve early suppression of the first item ignited in post-collision fires. Accurate information on the first item ignited in a fire would be of value. 
Some data are available from post-collision fire investigations, although it is very limited [Scheibe et al., 2001]. This work involved case studies of post-collision fires in vehicles. The data point to a wide range of fluid types that may have been the first item ignited such as transmission fluid, gasoline, motor oil, washer fluid, etc. The estimated time to ignition after collision was typically less than $5 \mathrm{~min}$, but this may be biased by eyewitness reports from people who were often not cognizant of a fire until it became visible and therefore quite large. Some very useful information on fire initiation and propagation is also available through the GM/DOT funded studies in the late 1990's and early 2000's, which investigated the detailed fire initiation and propagation in a large number of (about 11) vehicle crash and burn experiments [e.g., Jenson and Santrock, 1997; 1998; 1999; Santrock, 2001]. These experiments are extremely comprehensive in terms of instrumentation and analysis. The GM/DoT "Fire Initiation and Propagation Tests" are summarized by Digges and Stephenson [2006] and are described in 19 reports available at the DOT/GM website (http://dms.dot.gov/search/searchFormSimple.cfm) under Docket \# 3588.

More needs to be learned about fire initiation. Instrumented collision experiments would be very useful, but it is unlikely that such a program would occur because of the large amount of funding that would be needed. Another approach would involve searching data that is public, for example, through United States Department of Transportation (DOT) National Highway Traffic Safety Administration (NHTSA) sponsored crash test data or through accident reports such as the NHTSA Fatality Accidents Reporting Systems (FARS) or NASS (National Accident Sampling System), or other databases. The quality of the information is not clear in this regard. A study by Freidman used the FARS database and data from several states to estimate fire rates in collisions [Friedman et al., 2003; Friedman, 2005]. The data is limited to Police Accident Reports (PAR) and has very little detail about fires - certainly nothing on ignition source or first fuel ignited. The information in NASS is somewhat better, but is still very limited and the sample size in NASS is small.

Vehicle manufacturers do crash testing on a regular basis. They crash test their vehicles and the vehicles of their competitors. During testing, however, Stoddart solvent, a low volatility hydrocarbon, typically replaces gasoline and the engine may not be running during the tests. In addition, the battery may be disconnected and many underhood fluids drained. In part, this is done to avoid a fire, which can lead to significant financial costs associated with fire fighting and possible losses. Contamination of the crash test facility many of which are indoors and issues of worker safety may also be concerns. An instrumented crash test dummy, for example, contains sophisticated instrumentation and is extremely expensive. On the other hand, if crash tests were conducted with real gasoline, the engine running, battery connected, and all fluids full, then all crash tests become fire tests (in addition to the primary purpose of the test, which may involve airbag testing or rollover). This would greatly increase the knowledge base regarding the mechanisms of fire initiation in collision induced fires.

While little information is known about which fuel is the first ignited in engine compartment fires, it is fairly certain that the culprit in rear-end collisions typically is 
automotive fuel. Although fires associated with rear-end collisions are often attributed to underbody fuel fed fires, the nature of these fires is not well documented. Relatively little reliable quantitative information is available regarding leak rates, the size of a fuel trail, or the possible presence of fuel sprays. Although leak testing based on the Federal Motor Vehicle Safety Standard (FMVSS) 301 Fuel Integrity Test is routine, the test specifies the speed and configuration of various crash types. After the crash test, a rollover test is required. The vehicle is placed in a fixture and rotated about its longitudinal axis. In this test, there is no attempt to measure any fluid leakage other than motor fuel. Consequently, there is no data on the leakage of other fluids that may be responsible for engine compartment fires. Measurement of all fluid leakage in this test would increase the incentive to prevent all leakage in rollovers. It would increase knowledge about possible causes of vehicle fires and the requirements for suppression systems for underhood fires. The character of fluid leakage in a vehicle requires an improved understanding as this information could play a role in the design of experiments addressing the post-collision fire problem and ultimately possible solutions to the problem.

If a fire occurs and a suppressant is successfully deployed, there is a finite chance of reignition under certain conditions. Many conditions may affect the probability of reignition. This is essentially a heat transfer problem that involves cooling by the suppressant competing with the conditions that may lead to re-ignition including the temperature of a hot surface and its size and mass, the rate, temperature, and type of fluid that is impinging on that surface, and the flow rate and the temperature of the air near the hot surface. There are no comprehensive studies to date that assess the probability of reignition for post-collision engine compartment fire scenarios. Santrock [2001] reports detailed measurements on the ignition of underhood fluids on a hot metal surface. Unfortunately, that report does not include information on the actual temperatures of components in the engine compartment. To be meaningful, such measurements should be conducted with vehicle running with a load; idling is not enough. Information on the underhood temperatures in several types of vehicles is described by Fournier [2004]. Temperature information on used older model vehicles, not necessarily maintained to specification would also be of interest. It would also be useful to measure how quickly the surfaces cool after the engine has stopped, which would provide an estimate on the time of vulnerability to ignition, as well as possible re-ignition after suppressant delivery.

\subsection{Workshop on Vehicle Fire Suppression}

It is suggested that a workshop identifying and prioritizing fire suppression research ideas be convened. The workshop would endeavor to develop a consensus on the ideas and direction for new research in automobile fire safety. There is no documentation of such a workshop having taken place in the recent past. Much has been learned over the last decade in fire suppression research. A workshop should capitalize on that experience and more specifically, from vehicle fire suppression testing. Experience suggests that experts from all over the country would attend and actively participate in such a workshop [Grosshandler, 2002; Walton et al., 1999a; 1999b]. The outcome of the workshop could form the basis for consensus on the prioritization of future research in this area. 
A brain-storming session bringing experts with a variety of backgrounds together to discuss research needs in vehicle fire suppression and fire safety may lead to new directions or confirm ideas that have been previously expressed. It would be advantageous to invite experts with a range of backgrounds including both applied and fundamental suppression research and those from academia, industry, and government to discuss productive directions in fire suppression research.

The format for such a workshop might include presentation of a limited amount of background information defining the scope and magnitude of the vehicle fire problem and research to date. One session of the proposed workshop could address the issue of standard test methods (see Section 3.3 below). Currently, there are no accepted standard test methods to evaluate vehicle fire suppression technologies. The development of a sanctioned or consensus test method would presumably foster critical thinking in the identification of vehicle fire problems and provide a basis in the search for effective fire suppression technologies. The current practice of using of ad-hoc test methods will likely retard public acceptance of positive results in the development of suppression systems and impede advancement in the field.

An expected outcome for such a workshop would be a panoply of ideas on future directions in fire suppression and vehicle fire protection. While not all of the ideas can be expected to be constructive, it is likely that a significant number of ideas will be useful. The job of a workshop coordinator would be to encourage the prioritization of ideas based on scientific and engineering judgment of the participants. This type of workshop could probably be organized in three to four months and would require a modest investment of funds, but would yield confidence that best thinking was used before significant research investments were made. ${ }^{4}$

\subsection{Development of Standardized Fire Suppression Test Protocols}

No standard apparatus exists for evaluating the effectiveness of a suppressant in extinguishing post-collision vehicle fires. Detailed experimental test protocols for engine compartment and underbody suppression systems are needed to assist fire suppression researchers to address peculiarities of the automotive fire problem. The development of standardized test(s) or at least guidelines in the development of such tests would be useful, providing a common basis for evaluating the effectiveness of alternative fire suppression systems.

A suppression protocol can be designed such that suppression is extremely easy to achieve or nearly impossible to achieve, The key to the design of a test protocol is that the scenario is representative of the actual fire problem. This does not mean that the scenario should be "worst case," particularly if the worst case is very rare. If statistics and details associated with the post-collision vehicle fire problem are inadequately understood, then the development of a perfectly representative suppression test protocol is impossible. It is possible, however, to develop protocols and test suppression systems

\footnotetext{
${ }^{4}$ A brief Workshop on Fire Suppression Research Needs was held on the morning of Wednesday, April $13^{\text {th }} 2005$ at the SAE World Congress in Detroit, following paper presentations at Session C on Fire Suppression of the B-27 Forum. Appendix E of this report summarizes the discussion at the Workshop.
} 
based on incomplete information and engineering judgment in order to advance the understanding of safety systems.

There have been a number of experimental investigations looking at the effectiveness of vehicle fire suppression systems in both moving and static vehicles. Experimental protocols were developed. The apparatus in each of the experimental configurations included a fire zone and a suppressant delivery system. They are discussed in some detail below.

Hamins [2000] developed a number of experimental protocols to appraise the feasibility of fire suppression using a static uncrashed vehicle. A number of experiments were conducted to test the importance of operating conditions on suppressant effectiveness in the simulated vehicle fires. These included geometrical factors and suppressant delivery parameters. Long fuel trails extending beyond the confines of the vehicle and environmental factors such as wind were considered. The test protocols used actual fullscale non-running older-model vehicles in a static mode. Experiments focused on two configurations: underbody fuel-fed fires near the fuel tank and an engine compartment fire in which the fuel was dripping and pooling under the vehicle creating a threedimensional fire. For the engine compartment fire scenario, portions of the vehicle, such as the engine compartment including component surfaces were pre-heated by the test fire. The hood was bent or crumpled to create gaps on either side of the hood, simulating a post-collision situation. For the fuel tank fire scenario, a "fuel drip" was located on the fuel tank towards the middle of the vehicle rather than its rear. For the engine compartment scenario, a continuously energized hot surface was not present, so the possibility of "re-light" after suppression was not fully considered. The likelihood of relight in an actual situation would depend on many factors specific to the collision, the fire, and the suppression system. The experiments were relatively inexpensive by design. Both configurations used gasoline to fuel the fire. This set of experiments provided a basis for screening the effectiveness of various suppression technologies. In conjunction with the test protocols described below, it could form the basis for the development of a standard suppression test protocol.

Santrock and Hodges [2002] developed experimental fire suppression test protocols for moving and static vehicles. The experimental procedure for the moving vehicle suppression test repeated the protocol from a frontal crash test of a sedan that led to a fire [Jensen and Santrock, 1999; Santrock and Hodges, 2002]. No supplementary fire ignition mechanism was added to the vehicle. On-board detectors were used to discharge solid propellant gas generators (SPGG) mounted in the engine compartment. The experimental configurations and procedure are outlined in Jensen and Santrock [1999]. Subsequently, Santrock and Hodges [2002] repeated that test and replicated the fire event, which was attributed to power steering fluid as inferred by gas chromatographic, mass spectrometric (GC/MS) analysis. The ability to plan and repeat a crash/fire experiment should be a key element of any standard test protocol.

Ford developed a different approach, using moving vehicles. Their tests focused on the suppression of underbody fuel fed fires [Dierker, 2005; Ford, 2003c; 2006]. To evaluate 
the effectiveness of fire suppressants, Ford used both a fuel leak and an ignition device to assure that a fire occurred. The igniter was halted a finite time after ignition was assured. The duration of the ignition event is an important parameter, which may differentially affect the suppression effectiveness of some agents more than others, and has implications in terms of the possibility of fuel re-ignition or re-light.

Gunderson and DiMarzo [2004] tested the effectiveness of an underhood foam fire suppression system on a number of static, older-model vehicles. The vehicle was in an upright position except for one simulated rollover test in which the vehicle was on its head. Shallow metal trays, etiher rectangular or circular in shape and approximately $0.3 \mathrm{~m}$ diameter in size we refilled with $14 \mathrm{~mm}$ of gasoline and placed on the ground below the center of the engine compartment or on top of engine components near the battery location (towards the front of the vehicle). In the case of the rollover, the tray was placed on the hood, directly below the engine. The initiation of the suppressant foam release was concurrent with the ignition of the fire. In the open, enough gasoline was used to create about $5 \mathrm{~min}$ of burning, and the size of the gasoline was estimated as 80 $\mathrm{kW}$. In one control test, the foam suppressant was not deployed and the fire size continued to grow until the entire engine compartment appeared to be enveloped in flames. The surface of the burning fuel in these tests was two-dimensional, which is rather simplistic considering the complex geometry of vehicle engine compartments. In addition, Hot surfaces were not created in this scenario, so re-light (or re-ignition) was not addressed by this test protocol.

An appropriate screening protocol should include critical features of the vehicle fire problem. Several levels of standardized testing may make the most sense, with the first level of screening involving stationary vehicles and a second level of testing involving moving vehicles. A standardized test ought to be full-scale rather than reduced scale. Although full-scale experimentation is typically far more expensive than laboratory-scale experiments, it is not clear that a reduced-scale device would be appropriate for the variety of length and time scales involved in the vehicle fire suppression problem. The development of a reduced-scale apparatus must demonstrate the relationship between its results and the full-scale problem. In this sense, full-scale testing may be more practical than reduced -scale testing combined with scale modeling as cars are cheap and probably much cheaper than making a suitable scale model. For the post-collision fire problem, the apparatus would need to represent the panoply of post-collision conditions including the effects of a moving vehicle, a partially crushed vehicle geometry, a warm engine compartment and adverse weather conditions including possibly strong winds.

The issue of re-ignition must be addressed in the development of a standardized test protocol. Since so little is known about the heat transfer processes associated with the multitude of possible suppression and re-ignition scenarios, it is conservative to assume that re-ignition will occur unless an agent does a significant amount of cooling or if an agent physically separates the fuel, air, and ignition source for a significant amount of time. 
The idea of using moving/colliding vehicles to create a standardized test is an expensive proposition. Use of stationary vehicles for initial testing will reduce costs. Yet, the use of moving vehicles is important to capture real-world conditions that may play a defining role in the physics of the scenario. Ventilation in the engine compartments of a moving vehicle is different than in stationary situations and will undoubtedly affect suppressant performance. Ventilation will also be different if the engine is running with the radiator fan blowing. A possible fire suppression strategy may be to delay suppressant release until a vehicle has come to rest and the fan has been turned off. Ventilation effects may then be insignificant. Of course, this is not possible for all suppressant types. Powder panels, for example, are initiated by the crush of the accident itself, so testing of powder panels must be conducted in a vehicle collision scenario.

The idea of performing a suppression test on a vehicle that is running and under load is also an important consideration. The effects of a hot engine compartment and hot components may impact the flow behavior and effectiveness of an agent. For example, water based agents such as foam may vaporize. The temperature distribution within the engine compartment will create natural ventilation that will impact the flow field. Jensen and Santrock [1999] modified a number of vehicles to enable the motor to run during crash tests. They emptied fuel from the fuel tank and added a small gasoline reservoir and auxiliary fuel pump. Many of these crashed vehicles were subsequently burned as part of the General Motors crash and burn experiments [Wichman, 2003; Jensen and Santrock, 1999].

Assuring that a fire occurs during vehicle movement is a key part of the development of an experimental protocol. This has proven to be a contentious issue and must be meticulously addressed [Ford, 2004c; Fire Panel, 2004]. The attributes and relative effectiveness of powder panels is unclear at this time. In the case of the Ford/Fire Panel testing described in Section 2.6.2 above, disagreements about the effectiveness of the technology has led to a debate on the appropriate test protocol.

It would be desirable that the design of an experimental apparatus and protocol be developed through a consensus process involving multiple parties representing a variety of perspectives. It would also be useful to understand the details of previous research by Ford, General Motors, and others who have conducted crash/burn/suppression experiments. In this manner, the final design would be more likely to have merit and be accepted by vehicle manufacturers. This topic could be a key component of a Workshop (see above) on fire suppression.

While a static tests may be preferred, because it is cheaper, easier, and more repeatable, fluid flow effects associated with a moving vehicle may need consideration, particularly for some systems like the powder panel, in which suppressant delivery is directly linked to the collision. In other cases, dynamic testing may be needed to validate a static test method. 


\subsection{Fire Suppression Systems}

A finite number of fire suppressant types exist. These are discussed in Hamins [2000] and Bennett [1998]. Suppressant types include both traditional and emerging fire suppressants such as dry powders, clean suppressants, compressed liquefied halogenated compounds, water based foams, and water mist; and prototype devices such as powder panels, solid propellant generators and their hybrids, aerosol generators, as well as tubular extinguishers. There are many variations in each type of suppressant in terms of exact chemical type, thermophysical behavior, suppression effectiveness, engineering adaptability, and storage concerns. Some of these suppressant types are unlikely to provide post-collision vehicle fire protection [Hamins, 2000], whereas others may do so.

Very little agent mass is needed to extinguish a fire if it is delivered such that it encompasses a fuel source. Re-ignition protection, however, is also a concern for both underbody and engine compartment fires. In an underbody fire, a burning fuel trail poses the possibility of re-igniting a suppressed fuel puddle. In an engine compartment, reignition may occur due to a hot ignition source such as a battery or an electrically generated spark or arc. An agent that cools a hot surface, isolates the fuel from the ignition source, or isolates ambient air from the fuel and ignition source could afford protection in these cases.

To improve distribution of a suppressant, judicious engineering coupled with experimentation is needed. To provide re-ignition protection, a suitable suppressant must be selected. The following agents are suppression candidates that warrant further testing.

\subsubsection{Powder Panels}

The advantage of a passive system such as a powder panel rests in its simplicity. Fire protection systems comprised of several components (such as a suppression system that requires active detection) risks failure at each link in the system. While the powder panel tested by Ford may or may not have weaknesses, further testing of enhanced powder panel designs may be beneficial. The results of Cyphers and coworkers [2003] suggest that enhanced powder panel designs can improve powder distribution (see Section 2.6 above) and possibly suppression effectiveness.

There are a series of experiments that would be useful to consider to fully test this technology for vehicle fire suppression. It would be useful to test the effect of particle size distribution, powder type, powder amount, and enhanced powder designs on suppression effectiveness for fuel tank protection in conjunction with rear-end collision scenarios. A key component of the success of this technology will be inerting the ignition or suppressing a fire associated with a gasoline trail extending beyond the vehicle footprint.

Experiments by Hamins [2000] suggest that demonstration of this technology in engine compartment fire scenarios has a low probability of success. This is because the engine compartment scenario demands that agents be propelled to all corners and behind all engine components to provide comprehensive protection. Traditional powder panels do not provide momentum to propel the powder. Also, since the entire compartment needs 
protection, the panels would need to encase the entire compartment. A crash or thermally actuated panel may be useful for suppressing fires that occur just below the hood of an engine compartment. In fact, an after-market product named FirePanel uses the powder panel technology, and claims to have found a commercial niche in racing cars and police cruisers.

\subsubsection{Foams}

It would be useful to test the effectiveness of high expansion foams to defend against both engine compartment fires and underbody fuel fed fires. Some work is currently underway in this area by di Marzo (engine compartment) and Aerojet/Ford Motor Co. (underbody fuel tank protection). Previous work in this area was reported by Lim et al., [1997] who used a foam expansion ratio of 62 to extinguish engine compartment fires in uncrashed vehicles. Di Marzo suggests that this expansion ratio is too low [Gunderson and DiMarzo [2004]. A limited number of tests by DiMarzo are encouraging and have demonstrated the potential for foam as a suppressant of small flames, and certainly as a method to significantly reduce the risk of delayed underhood ignition. Ultimately, this technology remains to be proven in experiments that combine vehicle collisions and fires.

Some details of the Aerojet/Ford approach to fuel tank protection have been made public [Dierker, 2005; Ford, 2006], and a two suppressant approach has been implemented. The primary suppressant (SPGG) is used to knock-down the fire and a secondary suppressant (foam) is used to prevents re-ignition, possibly by a gasoline trail. The foam expansion ratio in this arrangement would have a bearing on the results. Detailed information on these effects would be helpful in suppression system design.

Di Marzo [2004] proposes using $\mathrm{N}_{2}$ to drive foam expansion, whereas it has been announced that Aerojet is using solid propellant generators in their apparatus [Ford, 2006]. This suggests that the foam is being driven by the SPPG effluent - composed mainly of $\mathrm{N}_{2}, \mathrm{CO}_{2}$, and $\mathrm{H}_{2} \mathrm{O}$. Di Marzo used a high expansion ratio foam with a volume expansion factor of nearly 200, in which the foam is essentially stable and a liquid water solution does not leak from the foam [Gunderson and DiMarzo, 2004]. The experiments of DiMarzo show that the foam system is capable of suppressing some types of fires in the engine compartment. Further work may be able to show that it is effective for suppression of ignition. In this sense, the results of this study lay the groundwork for further studies on under-hood fire suppression by foam.

It may also be useful to consider driving the foam expansion with gases other than nitrogen. There are many gaseous suppressants that are more effective on a volumetric basis than gaseous nitrogen. The more effective the suppressant, the higher the probability that fire suppression will be achieved. Although many agents are as effective as nitrogen on a mass basis, a more important criterion is effectiveness on a volumetric basis. Candidate agents must meet certain requirements as outlined in the report, such as Reynolds number, partial pressure and agent compatibility with tubing, fittings, etc. Agents that might be considered include $\mathrm{CO}_{2}$ or the low boiling point $\left(\mathrm{T}_{\text {boil }}<40{ }^{\circ} \mathrm{C}\right)$ fluorinated agents such as $\mathrm{CF}_{4}, \mathrm{CF}_{3} \mathrm{H}$, and $\mathrm{C}_{2} \mathrm{HF}_{5}$, which are significantly more effective fire suppressants than nitrogen on a volumetric basis. For example, $\mathrm{CO}_{2}$ and $\mathrm{C}_{2} \mathrm{HF}_{5}$ 
require $23 \%$ and $9 \%$ by volume (respectively) in the air stream to extinguish heptane cup burner flames as compared to $32 \%$ by volume for $\mathrm{N}_{2}$. Cold weather considerations may limit the use of higher molecular weight compounds such as $\mathrm{C}_{2} \mathrm{~F}_{6}$ and $\mathrm{C}_{2} \mathrm{HF}_{5}$, although they might be considered an option in warmer climates.

It should be noted that the combustion of fluorinated compounds leads to the formation of $\mathrm{HF}$, which is toxic. If it is determined that the suppression effectiveness of fluorinated driven foams are more effective than inert compounds $\left(\mathrm{N}_{2}\right.$ or $\left.\mathrm{CO}_{2}\right)$ for the engine compartment fire scenario, then measurements of HF in the passenger compartment during suppression would be necessary.

A further consideration is the use of high expansion foam to mitigate an underbody fuel fed fire. The use of a more effective agent than gaseous nitrogen would be useful in this case (see above). Protection may be afforded by rapidly filling the entire underbody footprint with a thick blanket of foam, which would effectively choke off the ambient air. Rapid delivery of the foam may be advantageous, depending on the rate of the gasoline leak. In this regard more than one release point for the foam may be beneficial. DiMarzo suggests that future work should include more tests on a wider variety of fires that start within the engine compartment, and try to extend the system to protect against pool fires that originate below the engine compartment [Gunderson and DiMarzo, 2004].

\subsubsection{Foam Freeze protection}

The viability of foam is limited by freeze protection. This is a significant issue that needs to be addressed. Addition of anti-freeze to foam may decrease the foam expansion ratio and may cause other significant penalties in terms of materials compatibility, suppression effectiveness, or other issues. Foam concentrate/water solutions (with anti-freeze) have been found to be limited to volume expansions of $\approx 3$ to 30 [Madrzykowski, 1999]. The expansion ratio is important because in a simplified sense, the larger the expansion, the larger the volume that can be filled for a given mass of foam. A comprehensive search for foam freeze protection by a research chemist may be of value.

Another approach would be to consider active heating of the foam solution under freezing conditions, perhaps electrically or by use of a heat exchanger, taking advantage of heat from the engine or the exhaust system. The effects of heating and temperature cycling on foam behavior and storage life would need investigation if this approach is considered.

\subsubsection{Solid Propellant Generators and Their Hybrids}

The use of hybrid technology with solid propellant generators offers an intriguing approach to the vehicle fire problem. The hybrid approach utilizes the effluent of the solid propellant generator to propel a suppressant, such as a compressed liquid or foam. Ford selected Aerojet's approach based on demonstration of their technology in suppressing an underbody fuel fed fire. It may be useful to test the Aerojet [Ford, 2006] approach on engine compartment fires. The primary suppressant (SPGG) would knock down the fire and a secondary suppressant (foam) would prevent re-ignition. Such an approach is the basis of the Ford system. 


\subsubsection{Other Suppressants}

The problem with most other fire protection systems (clean agents, halogenated compounds, powders, water mist, tubular extinguishers, etc.) is their failure to address protection from re-ignition by a gasoline trail in the case of the underbody fuel fed fire or hot surface re-ignition in the case of the engine compartment fire.

In an engine compartment, water mist could have some cooling effect on hot surfaces and lower the likelihood of re-ignition, but many parameters would play a role and there is little guarantee of success. The same is true for $\mathrm{ABC}$ powder, which interacts with burning materials to form a hard non-combustible coating. ABC powder $\left(\mathrm{NH}_{4} \mathrm{H}_{2} \mathrm{PO}_{4}\right.$, mono-ammonium phosphate) is unique among the powders. When in contact with a hot surface it reacts to form cross-linked polyphosphoric acid [Camino et al., 1994], a glassy impenetrable substance that can smother a smoldering fire and create a layer of insulation over a hot surface, which can diminish the likelihood of re-ignition. Other powders can also be expected to affect smoldering fires and prevent hot surface ignition, but mainly through physical processes rather than through a combination of chemical and physical processes. The success of these agents in preventing re-ignition will depend on may parameters including the hot surface temperature and the amount of powder that covers it. Like water mist, powders could lower the likelihood of re-ignition, but many parameters play a role and there is no guarantee of success.

\subsection{Other Issues}

\subsubsection{Economic Survey}

An economic study/survey to define consumer willingness to pay for on-board fire protection suppression systems would be useful to gauge. Demand from risk-averse consumers has driven expanded application of air bags in vehicles, such as in the use of side impact bags. A survey of consumers informed on the costs and benefits on the use of on-board fire suppression systems would inform vehicle manufacturers to the economic and marketing advantages in offering enhanced safety options. Decreased risk of fire injury and fatality must be weighed against decreased gas mileage, increased initial purchase costs, and maintenance issues.

It may also be possible to justify the expense of enhanced fire safety on vehicles based on possible reduction of cost to society. Property damage (vehicle and structures) due to vehicle fire is estimated to be over \$1 B [Ahrens, 2005]. The cost to the community in terms of use of the fire service for non-collision fires should also be considered. Public fire departments responded to an estimated 297,000 vehicle fires in the United States during 2004, almost $19 \%$ of the total number of reported fires. These fires caused an estimated 550 civilian deaths and 1,500 civilian injuries [Ahrens, 2005].

\subsubsection{Firewall on Demand}

Research supported through the NGP has pioneered the novel approach of using strategic placement of an intumescent material to reduce the cross-sectional area of the engine nacelle in an aircraft in the event of a fire. This approach creates an "instant firewall" and 
allows achieving required concentrations with smaller amounts of suppressant. Intumescent materials, however, can take tens of seconds to expand [Hamins, 1998] and may fail. This is because typical intumescent materials are one-dimensional in their expansion and any holes in these materials fail to close during this process. However, holes in the firewall are just one pathway into the passenger compartment. Another common pathway is flames breaking through the windshield and molten flaming thermoplastic dripping and igniting materials within the passenger compartment.

Consideration of other approaches to creating barriers should be considered. This may include the use of non-flammable lightweight materials that drop down from a vehicle body panel to the ground, forming a barrier that serves to confine subsequent release of a suppressant and prevent air entrainment to the underbody, for example. Another option that has been proposed is a non-flammable hood insulation that would detach under heat and subsequently fall, blanketing the engine compartment and smothering a fire. There has been no documented independent testing to demonstrate the effectiveness of this technology. Fournier and Bayne report on the flammability of some 20 underhood insulation blankets using the cone calorimeter [2006].

\subsubsection{Crashworthiness}

Much research remains to determine the crashworthiness and placement strategies associated with fire suppression hardware in post-crash vehicle applications. Some amount of empirical crash testing must be conducted to assure survivability and functionality.

\subsubsection{Computer fire models}

Despite a modest investment, results from the NGP program suggests that computational fluid dynamic simulations of fire suppression are not sufficiently developed to assist in the design of fire suppression systems for vehicle applications. The extension of computer fire models to vehicle fire scenarios is a long term project that may require a decade of investment to reap reward. Some modeling has been reported by Barnett [Wittasek, 1997]. Additional research is needed to develop effective suppression modeling tools.

\subsubsection{Passive Fire Protection}

Passive fire protection systems such as self-sealing fluid lines, enhanced crashworthiness of the fuel tank, and fluid shut-off devices are a viable strategy for post-collision fire protection that has not been fully investigated. Some recent research on a passive fire protection technology has been conducted by Ford. Ford tested an aftermarket fuel tank bladder and made their results public [Ford Motor Co., 2004b]. Fuel tank bladders are flexible liners that are intended to reduce the risk of fuel leakage after a collision. Ford tested the bladder with a foam insert, which prevented the liner from collapsing when the tank was not filled with fuel. Ford reported that bladders are required on some race circuits.

Ford evaluated the bladder tank technology offered in the aftermarket by "Fuel Safe" to Ford's internal fuel system test protocol, which is composed of a battery of 73 different 
tests. Testing was completed in June 2003 on 50 samples. A summary of important results from the Fuel Safe bladder tank testing is posted on the Ford web site [Ford, 2004b]. In summary, Ford expressed concern on the quality, durability and maintenance associated with the handmade bladder tanks that they tested. Issues included disintegration of the foam and conditions of engine "fuels starve" under certain conditions. Ford concluded that fuel bladders have never been successfully used in a mass-production, high-mileage or severe duty-cycle vehicle application and that as of now, the Fuel Safe fuel tank bladder does not meet Ford's fuel tank testing requirements.

Preventing post-collision fuel and underhood fluid leaks avoids the need for active fire suppression. It is a strategy that appears to have merit. Indeed, fuel tank protection may be the most practical approach to address the post collision underbody fuel fed fire scenario. Further research in this area may be warranted.

\section{Summary and Recommendations}

Much has been learned over the last decade in fire suppression research and more recently from vehicle fire suppression testing. This report attempts to summarize this research and to identify future research needs for automotive fire protection. This report on vehicle fire suppression research needs was not written with any particular dollar amount or timeline in mind. Nor does it propose one particular technology or line of research over another as the solution to the automotive fire suppression problem. Instead, the report proposes a series of interrelated activities, which could contribute to the development of an integrated program on automotive fire suppression research.

Data from NHTSA's Fatality Accidents Reporting Systems (FARS) shows that since 1990, there has been a significant reduction in rear-end fires from fuel leakage [Digges, 2007]. Among other reasons, this may be due to the implementation and improved effectiveness of a number of technologies that prevent crash-induced fuel leakage from severed lines connected to the fuel tank [Digges and Stephenson, 2007]. This suggests that the implementation of vehicle fire suppression systems may be most beneficial for underhood fires, particularly in frontal and rollover crashes. Past work has emphasized suppression of engine compartment fires and underbody fuel fed fires. Future research should also consider post-collision suppression of vehicle fires after rollover, as the fire risk in rollover is 2 times that in frontal crashes [Digges, 2007]. Underhood fires may rise in frequency as the amount of thermoplastic increases underhood, while the number of fatalities in rollovers has increased over the last two decades [Digges, 2007].

Through work with the automotive industry, it is clear that there is a tremendous amount of information in the field of fire safety that is proprietary. While this may be true in many endeavors undertaken by industry, the nature of safety related information is qualitatively different. Cooperation among industry leaders in this regard would promote accelerated development of technologies to improve life safety associated with mitigation of post-collision vehicle fires.

The implementation of an effective light inexpensive on-board fire suppression system would be a significant step in reducing fire fatalities, injuries, and property losses. One 
major impediment to vehicle fire safety is the lack of standards in this area. The only related existing requirement, the 1968 Federal Motor Vehicle Safety Standard (FMVSS) 301 Fuel Integrity Test for vehicles has not adequately addressed the post-collision vehicle fire problem as fire losses associated with vehicles are significant. The implementation of a standard performance test that directly addresses post-collision vehicle fires would allow the market to respond to this national problem, and allow the public to have confidence that a commercially-available technology is effective. 


\section{References}

Ahrens, M., "U.S. Vehicle Fire Trends and Problems,” National Fire Protection Association, Quincy, MA, August 2005; Report available at http://www.NFPA.org.

Bennett, JM, "Survey of Fire Intervention Technologies for Their Potential Application in Motor Vehicles," Report NHTSA 98-3588-31, 1998; available at http://dms.dot.gov docket 3588, report 31.

Bennett, JM, "Principles, Testing and In-Field Experience for the Fire Panel Fuel Tank Protection Device,” Paper 2005-01-1790, SAE 2005 World Congress, Detroit, April 13, 2005.

Bolt, W., Herud, C., and Treanor, T., "Halon Replacement Program for Combat Vehicles, A Status Report," Proceedings of the Halon Options Technical Working Conference, Alberquerque, NM, May 1997.

Camino, G., Luda, M.P., and Costa, L., "Developments in Intumescent Fire-Retardant Systems," Chapter 6 in Fire and Polymers II (ed.: G.L. Nelson), ACS Symposium Series 599, American Chemical Society, Washington D.C., 1995.

Cyphers, D.C., Frederick, S.A., Haas, J.P., Enhanced Powder Panels, Proceedings of HOTWC-2002 $12^{\text {th }}$ Halon Options Technical Working Conference, Albuquerque, NM, April 20 - May 2, 2002 (R.G. Gann and P.A. Reneke, Eds.) NIST Special Pub. 984, June 2002.

Dierker, J.B., Thompson, R.H., and Wierenga, P.H., Development of Ford Fire Suppression System, SAE World Congress, Fire Suppression Session (B-27 Forum), Paper 2005-01-1791, April 2005.

Digges, K.H., A Research Program to Improve Impact Related Fire Safety, 20th International Technical Conference on the Enhanced Safety of Vehicles (ESV), to appear, June 2007, Lyon, France.

Digges, K.H., and Stephenson, R.R., "Summary of Recent Research in Crash-Induced Vehicle Fire Safety,” Paper 2006-01-0551, SAE World Congress, Detroit, MI, April 2006.

Digges, K.H., and Stephenson, R.R., "Recent MVFRI Research in Crash-Induced Vehicle Fire Safety,” Paper 2007-01-0880, SAE World Congress, Detroit, MI, 2007.

Fire Panel Vehicular Fire Protection Systems, http://www.firepanelllc.com/frameset1.html, 2006.

Ford Motor Co., website on the Crown Victoria Police Vehicle, http://www.CVPI.com, 2004a. 
Ford Motor Co., Fuel Safe Bladder Tank Test Status, http://www.cvpi.com/bladder_tank test.htm, 2004b.

Ford Motor Co., Fire Suppression, http://www.cvpi.com/fire_suppression.htm, 2004c; reproduced in Appendix B.

Ford Motor Co. Automatic Fire Suppression System (60S), CVPI/Ford website (https://www.fleet.ford.com/showroom/CVPI/FireSuppression.asp) 2006; see Appendix D.

Fournier, E., “Under Hood Temperature Measurements of Four Vehicles,” Report No.: R04-13 b, Biokinetics and Associates Ltd., Ottawa, Canada, September 2004, Final Report for the Motor Vehicle Fire Research Institute, available at: http://www.mvfri.org/.

Fournier, E. and Bayne, T., "Flammability of Underhood Insulation Materials," SAE World Congress, Paper 2006-01-1011, Detroit, MI, April 2006.

Friedman, K., Kenney, T., Holloway, E, “Impact Induced Fires and Fuel Leakage: Statistical Analysis of FARS and State Data Files (1978-Present),” Friedman Research Corporation, October 2003, Available at http://www.mvfri.org/Contracts/friedman.html

Friedman, K., "Impact Induced Fires: Statistical Analysis of FARS and State Data Files (1978-2001); Paper 2005-01-01421, SAE World Congress, Detroit, MI, April 2005.

Grosshandler, W. L. (Ed.), "Fire Resistance Determination and Performance Prediction Research Needs Workshop,” NISTIR 6890, Sept. 2002.

Gunderson, J. and di Marzo, M., "Nitrogen Fire Suppression System for Automobile Under-hood Post-collision Fire Protection,” Fire Protection Engineering Department, University of Maryland, College Park, MD, Nov. 2004, Final Report for the Motor Vehicle Fire Research Institute, available at: http://www.mvfri.org/.

Hamins, A., "Evaluation of Intumescent Body Panel Coatings in Simulated Post-Accident Vehicle Fires," August 1998, Docket \# NHTSA-1998-3588-24, National Institute of Standards and Technology, Gaithersburg, MD.

Hamins, A., "Evaluation of Active Suppression in Simulated Post-Collision Vehicle Fires,” NISTIR 6379, National Institute of Standards and Technology, Gaithersburg, MD, November 2000; also available as Report NHSTA 98-3588-132, 2000 at http://dms.dot.gov docket 3588, report 132; or http://www.mvfri.org/Library/b-04.html

Halon Options Technical Working Conference (HOTWC). Albuquerque, NM, 1991-2003 
Hodges, S.E. and Simpson, G.D., "Effective Technologies for Fire Sensing and Suppression on Transit Vehicles," American Public Transportation Association (APTA) Bus Operations and Technology Conference, May 1995.

Hughes Associates, Inc., “Review of Ford Motor Company’s Test of Fire Panel in a Simulated Rear Collision Scenario,” Prepared for FIRE Panel Vehicular Fire Protection Systems, July 31, 2003. http://www.firepanelllc.com/pdfs/Review of Ford Motor Company FIRE Panel Test.pdf

Jensen, J.L. and Santrock, J., Evaluation of Motor Vehicle Fire Initiation and Propagation Vehicle Crash and Fire Propagation Test Program, NHTSA-98-3588-38; 1999; also available at http://dms.dot.gov docket 3588, report 38, or at http://www.mvfri.org/Library/b-03.html

Jenson, Jack L., and Santrock, Jeffrey, "Evaluation of Motor Vehicle Fire Initiation and Propagation Part 1: Vehicle Crash and Fire Propagation Test Program," General Motors Corporation (July 1997); available at http://dms.dot.gov docket 3588, report 38, or at http://www.mvfri.org/Library/b-03.html

Jenson, Jack L., and Santrock, Jeffrey, "Evaluation of Motor Vehicle Fire Initiation and Propagation Part 2: Crash Tests on a Passenger Van," (September 1998) Docket \# NHTSA-1998-3588-30, General Motors Corporation. available at http://dms.dot.gov docket 3588, report 38, or at http://www.mvfri.org/Library/b-03.html

Lim, Sung-Mook, Jung, Ki-Chang, Kang, Young-Goo, Kim, Hong, “A Study on the Assessment of the Performance of the Automatic Fire Suppression System Using the HCC-227ea Liquefied-Gas Filled AFFF Fire Extinguisher,” International Symposium on Fire Science and Technology, 1997, p. 590.

Madrzykowski, D., NIST, Personal Communication, 1999.

Porreto, J., Naples Daily News, Naples, FL., August 7, 2003; reproduced in Appendix A.

Ragland, C.L. and Hsia, H.-S., “A Case Study of 214 Fatal Crashes Involving Fire,” Paper Number 9X-S4-O-08, The Sixteenth International Technical Conference on the Enhanced Safety of Vehicles, Windsor, June 1998.

Santrock, J. and Hodges, S.E., Project B.14 - Demonstration of Enhanced Fire Safety Technology - Fire Suppression Systems, Part 2A: Evaluation of Fire Suppression Systems in a Full Scale Vehicle Fire Test and Static Vehicle Fire Tests. NHTSA-983588-202; 2002; also available at http://dms.dot.gov docket 3588, report 202; or http://www.mvfri.org/Library/b-14.html

Santrock, J., "Evaluation of Motor Vehicle Fire Initiation and Propagation Part 3: Propagation of an Engine Compartment Fire in a 1996 Van Passenger," (August 2001) Docket \# NHTSA-1998-3588-119, General Motors Corporation. http://dms.dot.gov docket 3588, report 38, or at http://www.mvfri.org/Library/b-03.html 
Santrock, J., and Hodges, S., "Evaluation of Automatic Fire Suppression Systems in Full Scale Vehicle Fire Tests and Static Vehicle Fire Tests,” Paper 2005-01-1788, SAE 2005 World Congress, Detroit, April 13, 2005.

Scheibe, R.R., Shields, L.E., Angelos, T., "Field Investigation of motor vehicle collision fires,” NHTSA-98-3588-164, 2001; also available at http://dms.dot.gov docket 3588, report 164; or http://www.mvfri.org/Library/b-02.html

Walton, W.D., Bryner, N., and Jason, N.H., "Fire Research Needs Workshop Proceedings,” Emmitsburg, MD October 20, 1999, NISTIR 6539, 1999a.

Walton, W.D., Bryner, N., Madrzykowski, D. Lawson, J.R., Jason, N.H. (Eds.), “Fire Service Needs Workshop Proceedings,” San Antonio, TX October 13-15, 1999, NISTIR 6538, 1999b.

Wichman, I., Prog. Energy Combust. Sci., 29, 247-199, 2003

Wittasek, Nathan B., Pehrson, Richard D., and Barnett, J.R., "Computational Fluid Dynamics Modelling of Post-Crash Vehicle Fires," (May 1997) Docket \# NHTSA-19983588-209, General Motors Corporation. 


\section{Appendices}

The appendices contain information that is cited in the body of this report. Information is typically taken from sites on the Internet. This appendices document the information by providing a complete citation and by reproducing it here. This is important, because information posted on the Internet is typically not archived, nor is it permanent. It is, however, useful in tracking the development and commercialization of fire suppression technology.

\section{Appendix A}

Naples Daily News, Naples Florida, Thursday, August 7, 2003.

\section{Ford to offer fire-suppression equipment on Crown Victoria police cars By JOHN PORRETTO, Associated Press}

TRAVERSE CITY, Mich. — Ford Motor Co. said Wednesday it will begin offering fire-suppression technology on its Crown Victoria police cars, which have been linked to numerous deaths in rear-end collisions that caused gas-tank explosions. Ford spokeswoman Carolyn Brown confirmed the new equipment would be used but said details were being withheld until a news conference Thursday in New York. At an automotive seminar Wednesday in this resort city, Ford president and chief operating officer Nick Scheele declined to discuss the new technology. About the Crown Victoria, Scheele told reporters, "It's a very safe vehicle, but it's got some very difficult usage conditions." Police unions and some political leaders have complained about the safety record of the Crown Victoria Police Interceptor, which is used by about 85 percent of all police departments. Since 1983, 14 officers have died in crashes when their Crown Victoria's gas tank caught fire after being hit from behind. In the past several years, the cars have been the subject of numerous lawsuits and a federal investigation.

Although Ford denies the cars are dangerous, about a year ago the company initiated a program of retrofitting older models with plastic shields designed to better protect the gas tanks. It is unclear if Ford will install the new fire-suppression technology in Crown Victorias sold to the public. The National Highway Traffic Safety Administration has said the car meets current federal standards that require a vehicle to withstand a rear crash at 30 miles per hour without leaking fuel. The agency also said the vehicle did not leak fuel during a test at 50 miles per hour, which the agency has proposed to be the new standard. Ford shares rose 13 cents to close at \$10.65 in trading Wednesday on the New York Stock Exchange. 


\section{Appendix B \\ (Ford Motor Co., Fire Suppression, http://www.cvpi.com/fire_suppression.htm, 2004c.)}

\section{Fire Suppression}

Ford is actively evaluating fire suppression technologies. Current fire suppression systems remain unproven for a mass-produced, high-mileage vehicle. Existing racecar systems are not adaptable because they require the driver to deploy the fire suppression system (driver's are typically incapacitated following rear crashes severe enough to produce a fuel leak) and involve a fire suppressant material that may not be appropriate in the police vehicle application because it is not breathable.

As part of the Police Officer Safety Action Plan, Ford tested eight fire suppression systems. Part of our testing involved fire-involved moving vehicles. Following a $75 \mathrm{mph}$ rear impact, the struck vehicle typically moves 100'-200', and our test protocol was designed to simulate such movement. Testing the competing technologies in a movingvehicle environment was important to our evaluation of the competing systems' rearworld performance. Our test protocol guaranteed both a fuel leak and ignition of the fuel so as to properly evaluate the fire suppressant technologies - many fuel leaks do not result in ignition, so a test of a fire suppressant system is invalid if an ignition source is not present. Significant conclusions reached during the testing include the following: Fuel leaks that begin near the point-of-impact may leave a 75-to-200-foot fuel trail to the point-of-rest of the vehicle.

Ignition of this fuel trail can occur when the deformed vehicles scrape the road surface and create sparks while passing through or along the fuel trail. Other ignition sources may be present after the time and point-of-impact. The ignited fuel trail can trace forward to the vehicle at its point-of-rest, which may be 50-, 100- or 200-feet from the point-ofimpact. An ignited fuel trail can initiate a fire at the vehicle's point-of-rest if there is continuing leakage of a sufficient amount of fuel at the point-of-rest. The fire is not intense at the passenger compartment until the vehicle is stationary, and unless there is a continuing leak at the point-of-rest. Challenges associated with packaging the fire suppression substance and system, while still allowing the vehicle to function effectively as a police vehicle, necessarily limit the quantity of the available fire suppression substance. The optimal time for deploying the limited amount of the fire suppression substance is near the point-of-rest, which can be seconds after and more than 200 feet beyond the point-of-impact. Wind, ground surface and road grade are factors in fire propagation. No vehicle fire suppression system can extinguish a fire fed by large quantities of gasoline.

In our testing for the vehicle application, liquid fire suppressants combined with surfactants performed better than foams or powders due, in part, to the ability of that substance to spread - like gasoline - beyond the direct reach of the deployment nozzles and to cover the gasoline. This combined substance more effectively reduced the risk of a 
re-ignition at the point-of-rest of the vehicle when the fire is not completely extinguished at, for example, the fuel trail or on the protected/outboard side of the rear wheels.

\section{Fire Suppression Technology-Next Steps}

As part of Ford's commitment to law enforcement to advance the state of the fire in fire suppression technology, Ford is taking the following steps: Ford has selected Aerojet as the fire suppression vendor to jointly pursue further development of this technology for the police vehicle application. Aerojet's technology uses a pyrotechnic gas generator to deploy a combination liquid fire suppressant and surfactant. A surfactant is used because it reduces the surface tension of the liquid fire suppressant, thereby enabling the liquid to spread more quickly and completely.

This technology was initially developed and tested for use in the interior of U.S. military armored personnel vehicles. The external application on the CVPI requires further development of this promising technology. Ford will likely use advanced electronics modules to measure post-impact vehicle movement and to determine the optimal time for deployment of the fire suppression system. As explained above, it is important that the limited quantity of fire suppressant material be deployed at or near the point-of-rest of the vehicle rather than only at the point-of-impact. The sophisticated electronics required for crash-activated and delayed deployment prohibit offering an after-market product.

In May 2003, Ford and Aerojet will conduct about 30 fire suppression tests on a CVPI to learn more about the effect of varying fuel quantity, fuel spill rates, re-ignition, discharge timing and shadow (fire behind the rear-wheel) effects. Beginning in June 2003, Ford and Aerojet will focus on integrated product development and design validation of the CVPI fire suppression system. While Ford and Aerojet will conclude a substantial portion of the design and development work by year-end 2003, it is premature to predict suitability of this technology to the CVPI application, let alone estimate pricing or timing. Ford will update the police community through our website, www.CVPI.com, as progress warrants.

Fire Suppression Technology-Fire Panel

In September 2002, plaintiffs' lawyers held a press conference announcing that the Fire Panel product successfully prevented ignition in a crash test. Because the fuel tank in that test was not full and ignition was not guaranteed, Ford does not believe that that test had engineering validity. Regardless, F.I.R.E. Panel subsequently approached Ford seeking an evaluation of its "Fire Panel" product. Ford evaluated the Fire Panel product consistently with its evaluation of the other fire suppression products.

Fire Panel is essentially a fire suppressant powder that is stored in a plastic casing taped to the fore side of the fuel tank. The plastic casing is intended to shatter, and thereby release its powder, in a high-speed rear impact when the fuel tank is pushed into the rear axle. After evaluating and testing this technology, Ford offers the following conclusions: Fire Panel releases its fire suppressant powder at the point-of-impact. Little or no powder is released at the critical time and place of the point-of-rest of the vehicle. 
The technology offers little or no protection against fires occurring at the vehicle's pointof-rest; if the fuel trail is ignited or any other ignition source is present after the time and place of impact, the Fire Panel technology provides little or no benefit.

The powder distribution can be adversely affected by wind and other weather conditions. Because the Fire Panel product insulates and is attached to the fuel tank, it may increase the temperature of the fuel and cause performance, durability and maintenance concerns. Moisture and road debris trapped between the $1 / 4$ " gap between the Fire Panel and the fuel tank could cause degradation of the steel fuel tank. Either of these concerns could lead to significant out-of-warranty maintenance problems, and potentially degrade fuel system safety.

The Fire Panel design did not adequately address mounting and fastener robustness. During one test, the entire Fire Panel actually detached from the vehicle upon impact and thereby failed to deploy its fire suppressant powder. Due to the inadequate mounting methods, the large plastic panel could also detach from the vehicle during normal driving, potentially creating a road hazard for other motorists. For these and other reasons, Ford does not support the Fire Panel aftermarket product offered to police fleets. 


\section{Appendix C}

\section{Ford Motor Company News Release}

\section{Available on the Ford website: \\ (http://www.aerojet.com/program/news/nr_080703fd_ford_introduces_industry_first_polic e_vehicle_tech.htm?program_ID=64) on July 28, 2006. FORD INTRODUCES INDUSTRY-FIRST POLICE VEHICLE TECHNOLOGY}

NEW YORK, NY, August 7, 2003 - Ford Motor Company and New York State Senator Nicholas Spano today announced an important step to protect police officers. During the 2005 model year, Ford plans to offer a fire suppression system as a factory option on Crown Victoria Police Interceptors. This is an automotive industry first. The announcement today is part of a holistic approach by Ford and the law enforcement community to reduce the risk of fire-related injuries to police officers from high-speed, high-energy rear crashes.

In recent months, Ford and representative members of the law enforcement community formed a Blue Ribbon Panel and Technical Task Force to reduce the risks faced by police officers in highway stops. Law enforcement personnel, independent experts, component suppliers and Ford personnel worked in a number of areas, including improving communications with a dedicated website - www.cvpi.com. The initial results, including the Upgrade Kit designed to shield the Crown Victoria Police Interceptor's fuel tank from vehicle components, were announced and published on the website for broad and quick dissemination. Ford also has developed a Trunk Pack ${ }^{\mathrm{TM}}$ to allow police officers to locate police equipment more safely. In addition, Ford engineers have worked with members of the law enforcement community to evaluate alternative traffic stop procedures in a manner that reduces the officer's exposure to danger. Ford also is encouraging state legislators to pass "move-over" laws in their states to protect officers in their line of duty. "Today's announcement is further evidence of Ford's commitment to police officer safety," said Sue Cischke, Ford Motor Company vice president, Environmental and Safety Engineering. "We have already advanced the safety of the Crown Victoria Police Interceptor well beyond governmental regulations or industry practice. However, until we, as a society, eliminate high-speed accidents, we will never eliminate the risk of fire. The potential of a fuel leak, while rare, is part of the risk of every high-speed accident. Therefore, we believe the actions we are taking to introduce fire suppression technology will help save lives."

Ford is developing a fire suppression system with Aerojet, a supplier for the United States military with the technology initially developed and tested for use in the interior of U.S. military armored personnel vehicles. The system uses advanced electronics and onboard sensors to measure post-impact vehicle movement to determine the optimal time for deployment of the fire suppression material. The system will be integrated into the CVPI's structure and electrical architecture. Ford and Aerojet conducted joint testing of many different fire suppression formulas and dispersal methods. Ford and Aerojet will continue to validate the effectiveness and reliability of fire suppression in an automotive application. "This is a monumental day for law enforcement across the country," Senator Spano said. "Ford deserves credit for their commitment to creating this technology. It 
represents a major first step in reducing fuel tank fires that have unfortunately taken the lives of officers across the country."

Additionally, the National Highway Traffic Safety Administration is joining with the International Association of Chiefs of Police to look at broader issues of police officer safety. Four members of the original "Blue Ribbon Panel" will participate in the IACP/NHTSA Joint Panel. They will focus on three areas initially: police procedures, police equipment and enhancing the safety of vehicles traveling on the nation's highways. Information from the Joint Panel will be available on the www.cvpi.com website. 


\section{Appendix D}

This appendix contains information released by Ford on the Automatic Fire

Suppression System (60S), which was an optional package on their 2006 model Crown Victoria Police Interceptor. This information was obtained from the CVPI/Ford website on July 28, 2006. (https://www.fleet.ford.com/showroom/CVPI/FireSuppression.asp;

\section{Fire Suppression}

The Ford Fire Suppression System is designed to reduce the risk of injury in high-energy rear impacts by deploying chemicals designed to suppress the spread of fire or potentially extinguish a fire. By doing so, it provides more time for occupants to either escape from a crashed vehicle or be removed from the vehicle by outside persons.

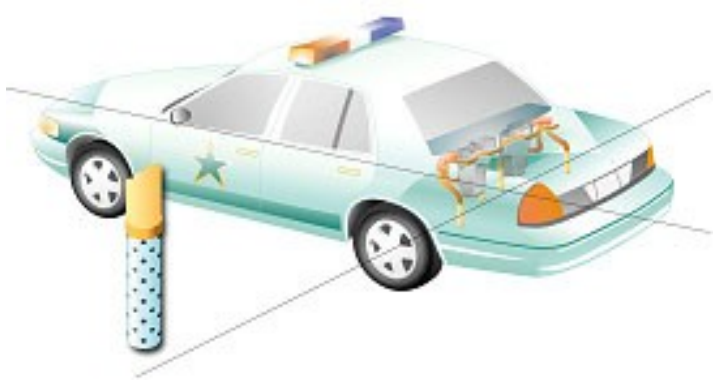

Ford offers the Fire Suppression System as a factory option. The FSS is an automotive industry first.

Development testing showed that the best time for deploying the limited amount of fire suppression substance is near the point of-rest, which can be seconds after, and more than 200 feet beyond, the point of impact. It also showed that liquid fire suppressants, combined with surfactants, performed better than foams or powders due, in part, to the ability of these substances to stay with the fuel source and to spread, like gasoline, beyond the direct reach of the deployment nozzles and to cover the gasoline.

The Ford system uses advanced electronics and on-board sensors to measure post-impact vehicle movement to determine the optimal time for deployment of the fire suppression material. The system is integrated into the Police Interceptor's structure and electrical architecture.

\section{Robust Test Procedure}

The Ford Fire Suppression system was tested in 75 mph rear impact collisions in which gasoline and ignition were artificially provided.

\section{Test Protocol}

A consistent, repeatable test protocol is required for testing in order to properly evaluate the system and any changes that are made during the development phase.

\section{System Sketch - Total Vehicle}


The system consists of:

- Two stainless steel containers that hold the fire suppressant material and gas generators used to pressurize and deploy the suppressant material.

- Two manifold assemblies, each with two deployable nozzles, which spray fire suppressant down onto the ground.

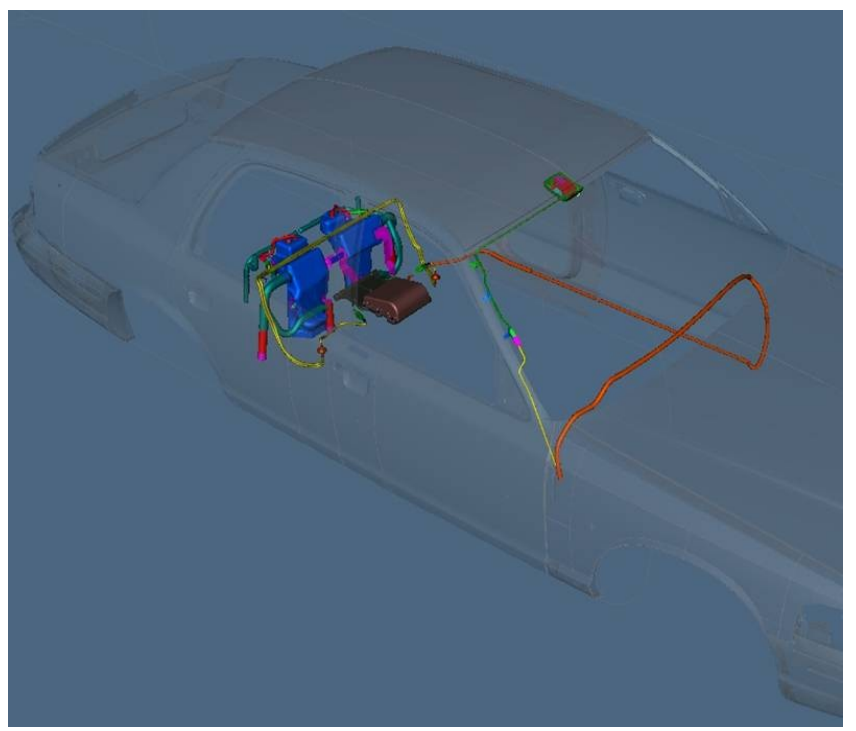

- An additional manifold, mounted high with two fixed nozzles, which sprays fire suppressant material up and into the body.

- The electronic control module (located under the rear seat). The module contains the rear crash sensor, the processing computer, and a large electrical capacitor for backup system power in case vehicle electrical power is lost.

- Two redundant wiring harnesses run between the control module and the gas generators. Each harness is armored to protect during a high-energy crash. The redundancy allows one to be damaged without impacting functionality of the system.

- The Manual Activation Switch is located on the headliner between the sun visors.

\section{How the System Works}

In the event of a very high speed, high-energy rear impact, a system of crash sensors and high speed electronic processors determines that the system needs to deploy. The system delays deployment until the ABS wheel sensors indicate the wheels have slowed and the vehicle is coming to rest.

If the vehicle speed sensors have been so damaged in the accident that they are unable to command deployment, a back-up timer will deploy the system six seconds after impact.

The fire suppression materials are stored in an unpressurized liquid state. When the deploy signal is given, two gas generators, similar to the gas generators used in airbags, generate high pressure gas. Suppressant and surfactant materials are then emitted through a system of manifolds and nozzles to suppress the fire.

Surfactant reduces the surface tension of the liquid fire suppressant enabling the liquid to spread more quickly and completely.

The system deploys:

- Automatically when a high-speed, high energy impact occurs at the rear of the vehicle 
- Manually when other situations require fire suppression

None of the materials used in the Fire Suppression System are hazardous.

\section{System Illustrations}

\section{Manual Activation Switch}

There is a covered manual activation switch mounted in a console on the headliner between the visors that can be used by vehicle occupants to manually deploy the system.

\section{Retrofits}

The system cannot be retrofitted for two reasons:

- The system is integrated with the vehicle's computer and a high-speed vehicle data bus that is new for the 2005 model year. This precludes retrofits onto pre-2005 model year vehicles.

- Modifications to the vehicle frame were required to support the additional weight at the mounting locations. Only vehicles built at the factory will have the frame modifications required to support the additional weight.

Fire Suppression Test Video (broadband connection highly recommended due to large file size)

This video is of a Fire Suppression System test conducted in March 2004. The system was activated by a fixed time trigger, not cessation of vehicle motion. There was no leak of fuel from the vehicle and no punctures of the fuel tank. Fuel for the fire, as well as the ignition source, were deliberately introduced as described in the Robust Test Procedure section.

- $75 \mathrm{mph}$

- $50 \%$ offset left

- 200 oz. fuel

- Fixed time trigger

- No punctures of the fuel tank

- Fuel and ignition source introduced by separate systems

- Fire suppressed automatically by onboard system

\section{System Limitations}

- $\quad$ The system has been designed and tested to withstand a $75 \mathrm{mph} 50 \%$ offset rear impact by a Taurus-sized vehicle

o In some crashes, including very high-energy crashes, the fire suppression system could be so damaged by the crash forces that it cannot deploy.

o Like any vehicle component, the Fire Suppression System may not withstand some crashes.

- $\quad$ The Ford Fire Suppression System was tested and designed under controlled conditions involving the artificial deployment of 200 ounces of gasoline.

o In some accidents, including those involving more fuel, the Ford Fire Suppression System 
may not be effective in controlling the fire.

- No vehicle can completely eliminate the risk of fires.

- You should not consider the vehicle "fire proof" because it is equipped with a Fire Suppression System.

- $\quad$ Like the Upgrade Kit, the Trunk Pack, and the Trunk Packing Considerations, Ford is offering the Fire Suppression System to reduce the risk of fires.

\section{Test Protocol}

A consistent, repeatable test protocol is required for testing in order to properly evaluate the system and any changes that are made during the development phase. For all of the rear crash testing, the following protocol was used:

- $75 \mathrm{mph}$ hit with a mid-size vehicle (Taurus)

- $50 \%$ offset left - The $50 \%$ offset is so that only one frame rail is engaged (worst case analysis)

- 200 oz. fuel

- Solid rocket motor, burning for $2-3$ seconds, to ensure fuel ignition.

- No punctures to tank - fuel introduced by separate system at a constant, known rate

- Fire suppressed automatically by onboard system

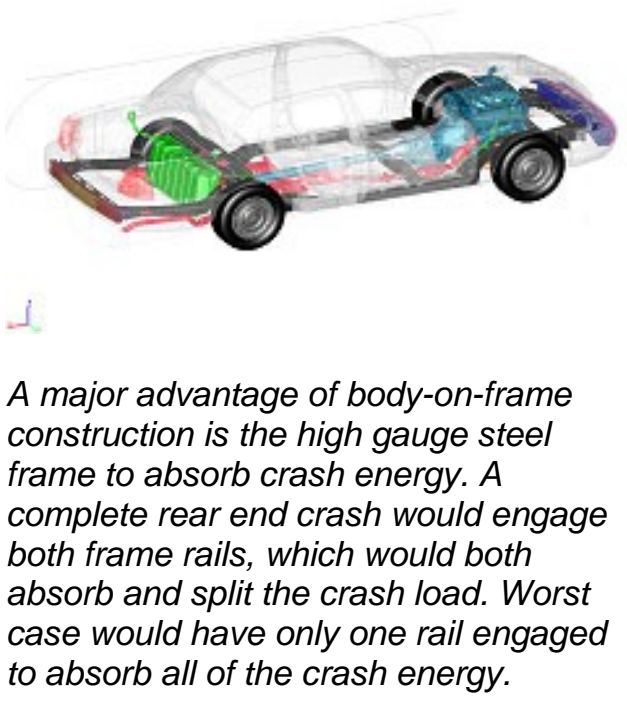

Manual Activation Switch

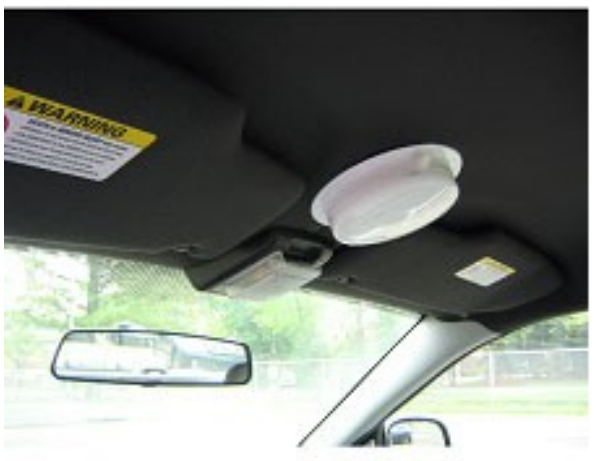

The Manual Activation Switch is located on the vehicle's centerline, just rearward of the windshield, and between the sun visors. 
A clear plastic hinged cover protects the switch from accidental activation. It can be pushed or pulled open
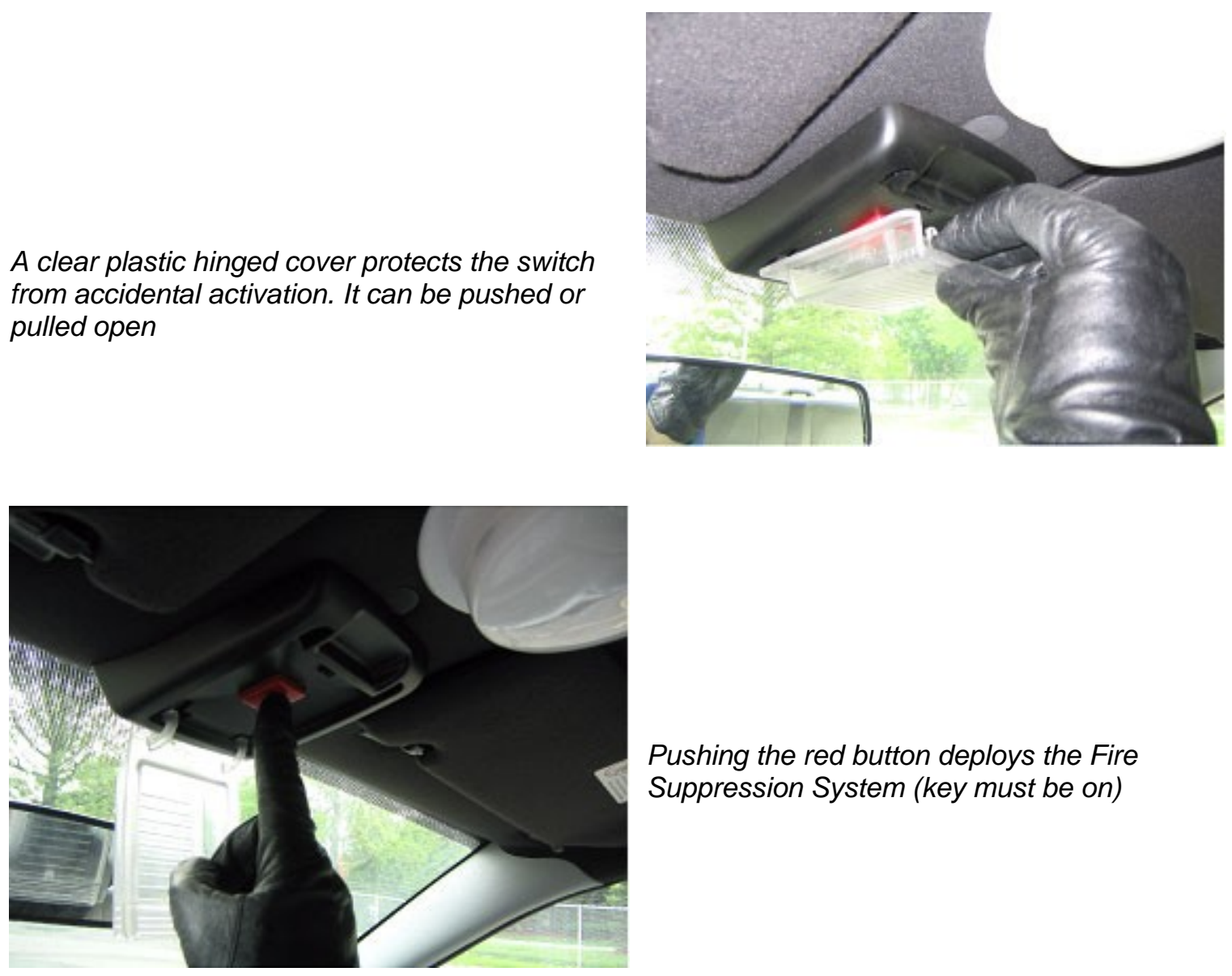

Pushing the red button deploys the Fire Suppression System (key must be on)

The system can also be activated by a $20 \mathrm{lb}$. Force without opening the cover

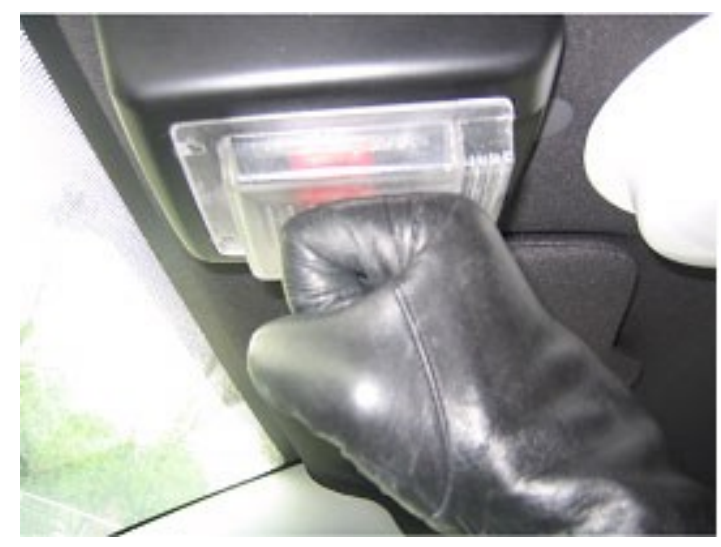




\section{System Views}

Below are various views of the Fire Suppression System.

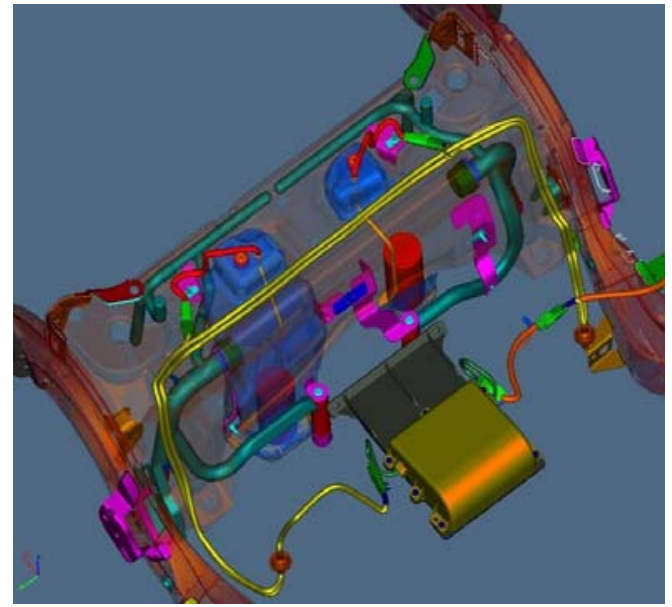

Major system components - rear of vehicle

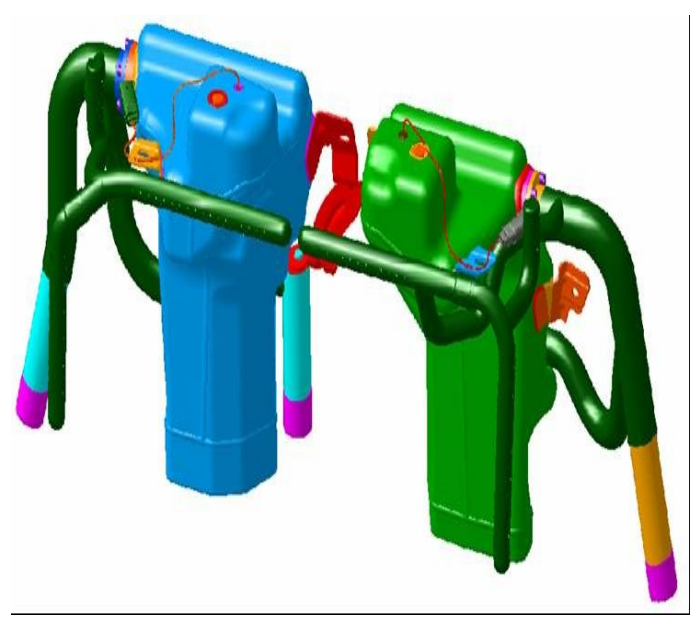

Tanks and nozzles

Four lower nozzles are used in the deployment of the system. They are held in an elevated position so as not to decrease vehicle ground clearance until needed. They are covered with a protective cap until the system deploys. When the system deploys, the force of the gas generators deploys the nozzles, as shown in the diagram on the right, so that the fire suppressant material is spread below the vehicle.

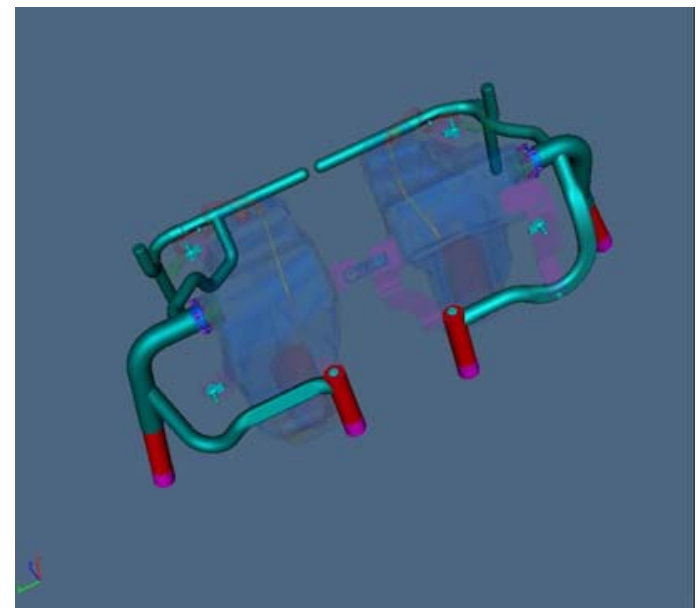

FSS Nozzles - Stowed

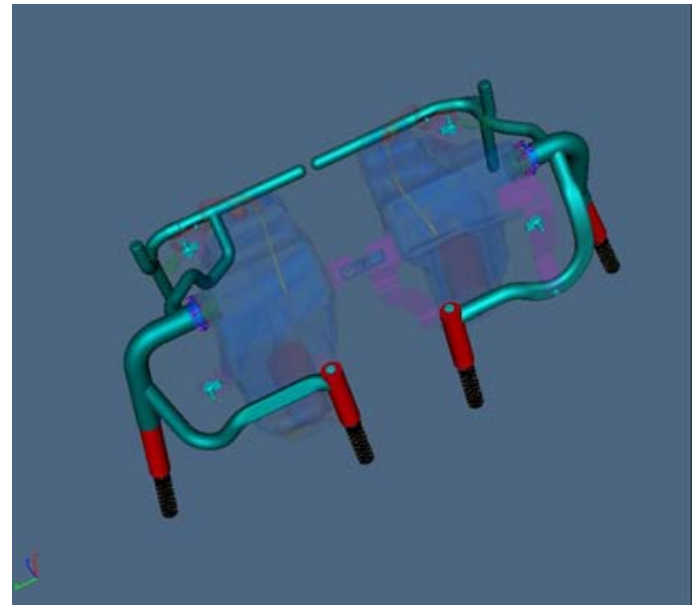

FSS Nozzles - Deployed 


\section{Robust Test Procedure}

The Ford Fire Suppression system was tested in $75 \mathrm{mph}$ rear impact collisions in which gasoline and an ignition were artificially provided.

To effectively design and evaluate a fire suppression system, ignition sources and fuel must be present. Ford's testing involved spraying 200 ounces of fuel, under pressure (60 psi) up and under the vehicle to simulate fuel migration as seen in real world crashes. Ford tested with 200 ounces of gasoline both because it was consistent with the leakage experienced in some field and test vehicles, and

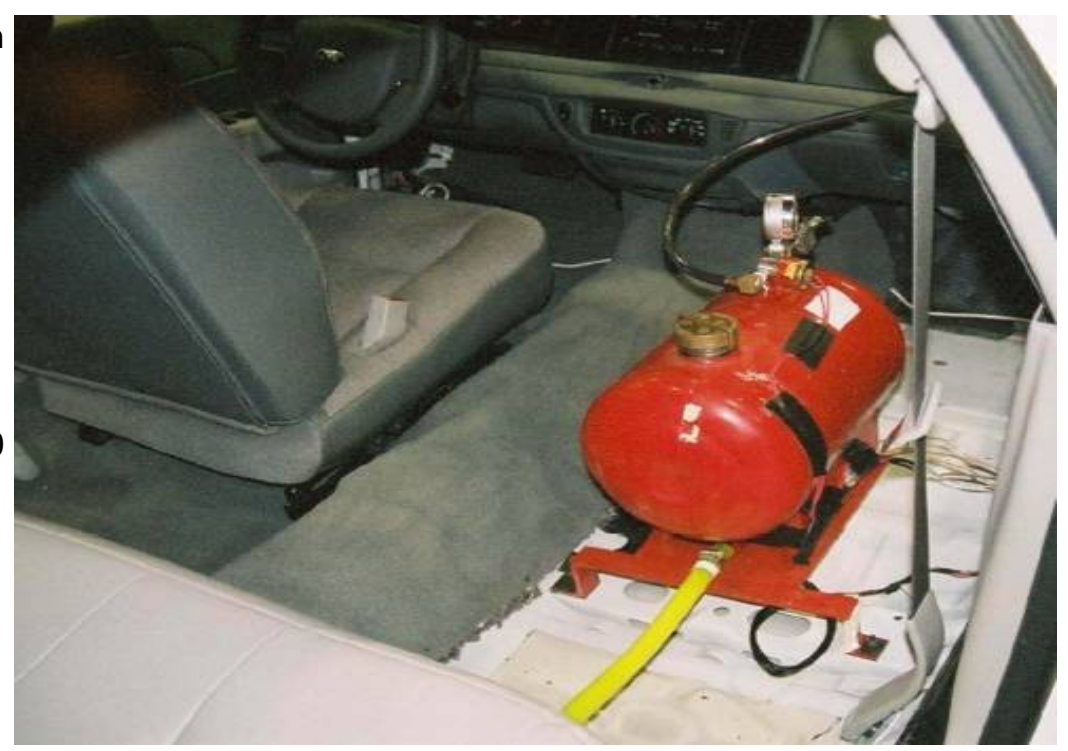
because it was determined to be within the outer limits of technology. A rocket motor with a burn time of two to three seconds was used to reliably ignite the fuel.

Above is a photograph of the test fuel cylinder (shown in red) used to deliver fuel during the development testing. It delivered 200 ounces of pressurized fuel to ensure fuel for a fire at repeatable delivery quantities. 


\section{Appendix E}

\section{Summary of Workshop on Research Needs for Suppression of Vehicle Fires}

A brief (about two hours in duration) Workshop on Fire Suppression Research Needs was held on the morning of Wednesday, April $13^{\text {th }} 2005$ at the SAE World Congress in Detroit, following paper presentations at Session C on Fire Suppression of the B-27 Forum. This Appendix summarizes the results of the Workshop.

Much has been learned over the last decade in fire suppression research and more recently from vehicle fire suppression testing. The panel discussion was intended to capitalize on that experience and to provide a forum to discuss the strategies, technologies, procedures, best practices and R\&D that can significantly improve fire suppression effectiveness in vehicles.

The Panel followed the Session on Fire Suppression by design. Four papers were presented at the session [Bennett, 2005; Dierker et al., 2005; DiMarzo and Gunderson, 2005; Santrock and Hodges, 2005]. These papers formed the basis for the panel discussion as they underlined the state of the art in fire suppression research, development, and testing. Each of the four papers were unique and represented a significant contribution to the knowledge of vehicle fire suppression research.

The goal of the panel discussion was to identify barriers that impede advancement in the application of fire suppression technologies to vehicle fires with emphasis on postcollision vehicle fires. In this regard, the Panel was invited to explore a number of general issues, including the following:

- Review of new advances in vehicle fire suppression and continuing challenges

- Recent developments in fire suppression technology in other applications

- Identification of technological advances and further research that is needed to address the vehicle fire suppression problem

- Establishment of standard test protocols to characterize suppression system performance

- The roles of industry, federal agencies and standards committees in establishing standard test methods

- Special needs associated with alternative fueled vehicles

- Opportunities for collaboration

The panel included scientists and engineers with a diversity of expertise and background, which should stimulate lively discussion. Representatives from the automotive industry were invited to participate (Dr. Joeseph Dierker, Ford Motor Co., Dr. Jeffrey Santrock, General Motors), but they declined. Professor Marino DiMarzo (University of Maryland at College Park) was invited and planned to attend. Unfortunately, he became ill and did not attend. The list of panel participants included the following people:

- Michael Bennett, Bennettech 
- Richard Gann, NIST

- Steven Hodges, Kidde Dual Spectrum

- Leland Shields, Leland Shields Inc.

- Archibald Tewarson, FM Global

- Paul Wierenga, Aerojet

- Anthony Hamins, NIST (Panel Moderator)

The Panel included experts from the combustion fire suppression community as well as those currently doing research on vehicle fire suppression. The experience of the panelists represented about 150 collective years of knowledge in fire research and development.

A list of ten discussion questions was submitted to the panelists several weeks before the commencement of the Workshop. The questions were designed to focus and promote discussion during the Workshop. The questions were the following:

1. What additional research is needed, either fundamental or applied, that would accelerate implementation of fire suppression technologies?

2. What phenomena need further understanding to accelerate the development of fire suppression technologies for post-collision vehicle applications?

3. Are there fire scenarios (ignition, materials, etc.) in post-collision vehicle fires that have not been adequately addressed by the suppression research to date?

4. What are the prospects for implementation of fire suppression technologies in the passenger or commercial vehicle marketplaces? Can this process be accelerated and streamlined?

5. Would the development and institution of standard test methods for post-collision vehicle fires be useful in the development of suppression technologies?

6. Is special research needed to address suppression in alternative fueled vehicles?

7. Where is funding for post-collision vehicle fire suppression research going to come from in the future?

8. How do fire scenarios involving post-collision passenger vehicles differ from fire scenarios involving buses, off-road, and military vehicles that carry fire suppression systems?

9. Are there technical challenges that hamper further progress in the development of suppression technologies?

10. Comments on the papers presented at the Suppression Session.

The Session was split into several parts. Each of the panelists was introduced. A brief "opening” statement was made by each panelist regarding the state of fire suppression of vehicle fires in general, and thoughts on the character of the papers presented during the Suppression Session. Opening statements were focused on general issues, rather than a recapitulation of the material that was presented during the paper presentations. There was no minimum suggested duration for the statement. The duration of the opening statements varied, with a minimum of a few sentences, and a maximum of several minutes. Participants were encouraged to consider preparing one or two PowerPoint slides for the opening statement, and two of the participants did so (Hodges and Shields). 
While many of the panelists focused their commentary on the papers that had just been presented as part of the Fire Suppression Session (B-27 Forum) that took place immediately preceding the Panel Discussion, others presented their unique perspective on other fire suppression issues. The participants discussed challenges and progress in the suppression field. Hodges presented the results from experiments examining the effectiveness of suppressants on fast combustion situations. Shields presented information related to the incidence of fire and collisions. Others highlighted the importance of flammability of materials that are found underhood. Response from the audience indicated that they were interested in hearing the thoughts of the panelists on the challenges and progress in the field.

- Tewarson asserted that both passive and active approaches to fire mitigation should be considered. He argues that passive system approaches were needed as a simple way to reduce injuries due to fire spread from a vehicle underhood to the passenger compartment. Tewarson felt that the time was ripe for further advances in reduction in fire losses with the progress demonstrated by the papers presented during the Fire Suppression Session, and that through a combination or synergy of work among the General Motors/DOT research program, the University of Maryland program, and the Ford program, substantial progress has been made.

- Shields presented information on fire suppression from a fire investigator's perspective. He emphasized practical considerations including the importance of maintenance issues when discussing the addition of on-board suppression systems. He asserted that in terms of practicality, testing must assure that unintended consequences are avoided. He was concerned about issues of visibility, toxicity, and service injuries. For example, if a powder system is used underhood, how would false discharge affect visibility? Shields asserted that sources of field data such as databases of collisions should be analyzed by multivariate techniques to look at important events that may lead to a fire. He felt that the reliability and accuracy of the databases should be evaluated.

- Bennett discussed the evolution of air bag technologies and the willingness of the public to pay for enhanced safety features on vehicles. He argued that a wellcrafted market study needs to be undertaken to determine exactly how much the public is willing to pay for vehicle fire safety. Bennett went on to argue that if the amount invested in safety systems was proportional to the rate of injuries associated with fire, then spending on fire safety intervention would soar, and presumably losses would be reduced.

- Wirenga cited his experience with military systems and how preliminary technology developments progress in fits and starts, initially costly, but more economical with time as engineering optimization has time to mature.

- Gann suggested that many issues should be considered. Citing 30 years of fire statistics, he indicated that the number of fatalities had changed little over this period, and at the same time the number of miles driven and the number of roads had increased significantly. He suggested that the substitution or modification of flammable vehicle fluids and thermoplastic materials should be considered. He asked what fraction of the annual fire fatalities would be eliminated if underhood 
fluids were less flammable or made entirely non- flammable, or if flammable materials were substituted with materials with appreciably improved fire resistant behavior.

- Hodges presented research results on heavy-duty vehicle fire protection, with emphasis on the US Army M1 Abrams tank. Video was presented of experiments examining the suppression of fuel explosions in an armored vehicle. An analogy between suppression in this system, transit buses, and automobiles was made. Hodges cited National Vital Statistics from 2002, and challenged the audience to address the practicality of working on fire related fatalities and injuries associated with vehicle collisions, from the perspective of automobile manufacturers. The point being that fire related losses represent only a small fraction of total collision-related losses.

At the conclusion of the statements made by the Panelists, participation by the audience was encouraged. To promote discussion, the ten questions listed above were posed to the audience.

The number of people in the audience was rather small and numbered no more than about 20 at its peak. Yet, through their questions and comments during the discussion, it was clear that the audience members were highly knowledgeable about the vehicle fire problem.

Bennett suggested that FARS statistics should be expanded to cover the full economic cost of vehicle fires, including injuries, lost work time, insurance costs, etc. He went on to argue that the fire safety community should work to quantify the lives saved through enactment of FMVSS 301.

One audience member highlighted the problem of developing accurate statistics on the vehicle fire problem. The person suggested that death certificates should be precise and specify fire as the cause of death when that is the case. The person noted that vehicle deaths were second only to deaths by fire in homes; and that $2.9 \%$ of deaths in vehicles involved fire.

One person asked the audience to look beyond post-collision fires as the community attempts to better represent the magnitude of the vehicle fire problem. He stated that about $10 \%$ of vehicles in a salvage yard were due to fire damage. This participant highlighted the need for some kind of standardized test for fire suppression. He challenged the community to better define the requirements of a standardized test, asking if DiMarzo's 80 kW fire was an appropriate test or if Ford's method that used 200 ounces of gasoline was suitable. Wierenga responded by saying that the method should depend on the vehicle type and make, and that a single pass/fail test would be unsatisfactory. Wierenga went on to say that the test should not favor one technology over another, but should be a fair test based on actual fire conditions.

The moderator posed the question as to whether standardized tests should be static or dynamic. Hodges responded by recounting that the military does realistic testing, trying to simulate actual conditions, and going as far as using live ammunition in their suppression tests. Tewarson suggested that standardized tests may not be needed. Shields contended that a systematic research project should prioritize conditions linked 
with post-collision vehicle fires. The implication is that that information is needed to design realistic standardized tests. Gann stated that the fire protection community does conduct standardized testing. He suggested that an important consideration may be ventilation effects.

Bennett made the comment that at least some testing must be dynamic, as some systems operate in response to a collision, such s self sealing fuel lines or powder panels.

One person in the audience brought up fuel tank testing. There was little follow-on discussion.

The question of the use of simulation in lieu of experiments was discussed. Tewarson felt that it is not possible to do accurate and complete fire suppression modeling, because it is too complex. Other suggested that coarse calculations may give guidance for system design, or at least in the design of effective and insightful experiments. Gann agreed that suppression modeling was not accurate at this time, but he suggested a pragmatic approach in which simplification of the flow field, the ventilation, and fuel sources may yield useful information in the design of suppression systems.

One panelist challenged the community by suggesting that the financial benefits of fire safety systems should not be a focus for several reasons, including the decreasing rate of fire losses as safety as vehicles generally improve.

Some amount of discussion addressed issues associated with changing the problem of the lack of research and development funding. One panelist argued that it may be possible to justify increased investment on fire safety systems based on savings in non-collision situations. Wierenga confirmed that automobile manufacturers are slowly recognizing the financial benefit of safety. Another panelist suggested that a full-blown economic study of the cost of vehicle fire losses to the economy be considered including the cost of injuries directly attributed to fires in vehicles. Others suggested that the financial benefits of the FMVSS 301 should be estimated. One member of the audience suggested that an argument for funding should consider the occurrence of non-crash fires, the long response time for emergency response in rural areas, that fires under bridges can cause extensive property damage, that fire create toxic pollutants and run-off, and that vehicle fire are a possible sources of forest fires.

At the end of the session, the moderator performed a survey of the audience, seeking information on the number of people who represented the automobile industry in the audience. Not one person responded affirmatively. It is apparent that a great deal of education will be necessary to convince automobile manufacturers that $R \& D$ in fire safety is a good investment.

In summary, the panel discussion addressed a number of important points. Yet, some amount of focus was lost in the discussion, as the key questions (see numbered points above) were only partially addressed. This may have been related to the format of the Workshop, which was perhaps too brief (about two hours in duration) to delve in-depth into this relatively complex subject matter. From the discussion, it was clear, however, that many challenges, both technical and political remain, before fire losses associated with vehicles are to be significantly reduced. 